\title{
A Law of Physics in the Classroom: The Case of Ohm's Law
}

\author{
Nahum Kipnis
}

Published online: 25 February 2009

(C) Springer Science+Business Media B.V. 2008

\begin{abstract}
Difficulties in learning Ohm's Law suggest a need to refocus it from the law for a part of the circuit to the law for the whole circuit. Such a revision may improve understanding of Ohm's Law and its practical applications. This suggestion comes from an analysis of the history of the law's discovery and its teaching. The historical materials this paper provides can also help teacher to improve students' insights into the nature of science.
\end{abstract}

\section{Problems with Ohm's Law in the Classroom}

This paper is about one of the fundamental laws of electricity discovered by Georg Simon Ohm (1789-1854), which plays a tremendous role in practical applications of electricity and electronics. It focuses on proper places of two versions of Ohm's Law called the 'law for a part of a circuit' and the 'law for a whole circuit' in teaching electrical circuits. One of the purposes of this paper is to show that students' learning of electrical circuit may be improved by changing the current emphasis on Ohm's Law for a part of the circuit to that of Ohm's Law for a whole circuit. The author has in mind advanced high school or college classes.

A number of studies pointed out students' difficulties in learning electrical circuits and basic electrical concepts and offered various means for their alleviation (Cohen et al. 1983, Shipstone 1984, McDermott and Shaffer 1992). Among the issues at stake are such as proper ways of introducing the idea of closed circuit, current, voltage, and resistance; the role of experiment, of qualitative mental problems, of students' pre-scientific ideas, and others. A comprehensive and systematic review of this field supplemented by novel ideas deserves a separate study. This article, however, is limited to teaching Ohm's Law, and while some of the issues mentioned above will come up here, they will be dealt with only in connection with Ohm's Law. Until now, difficulties with learning Ohm's Law have not

N. Kipnis $(\bowtie)$

10531 Cedar Lake Rd Apt. 308, Minneapolis, MN 55305, USA

e-mail: nahumk@gmail.com 
been differentiated from those with other concepts and laws of electric circuits. For instance, while the sequential model of electric current, so popular with students and researchers, implies a possible connection with Ohm's Law for a part of a circuit rather than with the law for the whole circuit, apparently no one checked this connection (Driver et al. 1994, pp. 122-23). Nor any special emphasis has been made in new teaching materials on a need of proper learning the skills of electrical measurements to prepare students to future professions (Shaffer and McDermott 1992).

Students' difficulties with Ohm's Law begin with misunderstanding of the different roles played by the two laws of electricity that bear Ohm's name. The law for a part of a circuit is expressed by the equation

$$
I=V / R
$$

where $I$ is current (also intensity of current) through a conductor, ${ }^{1} V$ is potential difference (also drop of voltage) between the ends of this conductor, and $R$ is resistance of the conductor. It could be illustrated by a diagram in Fig. 1a, which means that whatever happens outside this conductor, the numerical relations between $I, V$, and $R$ remain the same. Unfortunately, textbooks and Internet websites ${ }^{2}$ associate this law with a different diagram (Fig. 1b). This diagram implies that the law is valid for a closed circuit with a single resistance and a battery supplying a constant potential difference $V$. While relying on this diagram students have difficulties with such a simple assignment as measuring intensity of current $I$ and potential difference $V$. In particular, since Fig. 1b implies that other parts of the circuit have no resistance, students may connect the voltmeter in a variety of ways (for instance, between $\mathrm{A}$ and $\mathrm{B}$, or B and $\mathrm{C}$, or $\mathrm{C}$ and $\mathrm{D}$ ) and obtain different potential differences. To avoid such a situation the teacher should inform students that every part of the circuit has some resistance, and, therefore, they should use the diagram in Fig. 2. Here $R$ is the resistance of a conductor to be measured, $R_{\mathrm{A}}$ and $R_{\mathrm{V}}$ are resistances of an ammeter and a voltmeter, $R^{\prime}$ is an additional resistor necessary to transform an ammeter into a voltmeter (see further), $R_{\mathrm{w}}$ is the resistance of conducting wires (leads), and $r$ is the internal resistance of a power source.

Such a circuit would correspond to Ohm's Law for the whole circuit

$$
I=E /(R+r)
$$

where $R$ usually means the total resistance of the external circuit, $E$ is the electromotive force of the power source, and $r$ is its internal resistance.

As a rule, teachers introduce this law, if at all, after the law for a part of a circuit. Yet, as shown further, Ohm first discovered the law for the whole circuit and such a sequence was more logical than the one currently employed in teaching. It turns out that students need Ohm's Law for the whole circuit to be able to do electrical measurements properly. Indeed, to achieve correct results, students should understand how to connect an ammeter and a voltmeter, how to select them so that their internal resistance would not affect the results of measurements, when to take into account resistance of connecting wires and of the power

\footnotetext{
1 Unless specified otherwise, 'conductor' means in this paper a body transferring electricity rather than a property to do so. This term has a wider use than 'resistor' that came from electronics.

2 Whether teachers like this or not, students increasingly view Internet as an easily accessible resource of scientific information. To make teachers aware of this, I mentioned in this paper a few websites which provide information related to Ohm's Law, and which students may refer to when discussing the subject in the classroom. See, for instance, the following materials on circuits with a single resistance and batteries without resistance: http://www.cadvision.com/blanchas/education/www/ohm/1stye.htm
} 
Fig. 1 An ideal circuit: (a) a part of the circuit, (b) a complete circuit
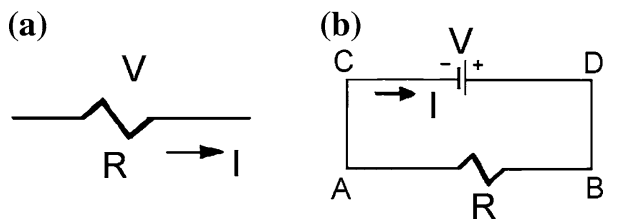

Fig. 2 A real circuit

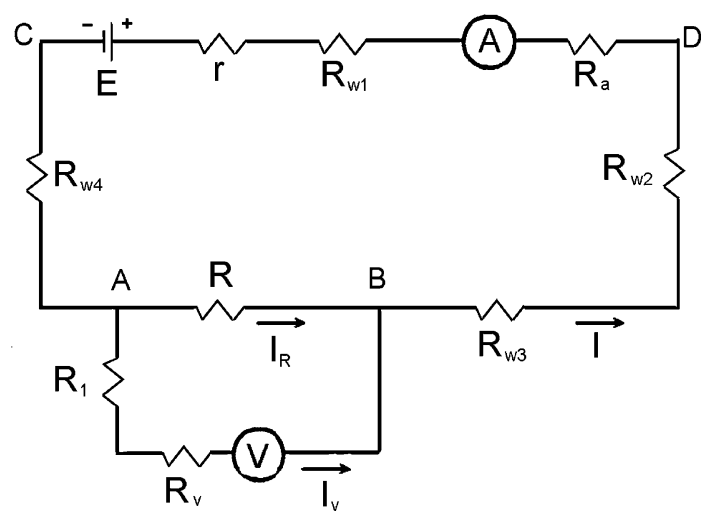

source, and so on. In other words, even to measure a single resistance a student have to think of the whole circuit, which implies Ohm's Law for a whole circuit.

Yet, many teachers assign measuring current and voltage, as, for instance, without (or prior to) introducing the law for a whole circuit. To enable students to do measurements these teachers pre-select a correct set of apparatus and describe the procedure in such detail that students cannot make a wrong connection. As a result, students succeed with their measurements but remain unaware of difficulties that could have prevented them from obtaining the correct results. When left to their own devices, for instance, when working on an individual project, they will inevitably fail.

While Ohm's Law for a part of a circuit offers no help in experiment, it also has inherent theoretical difficulties. One of them is about a proper formulation of this law. Currently, two versions can be found in different textbooks. Formulation One states that, current through a conductor is proportional to potential difference at its ends. A consequence of this law is $R=$ const.

According to the Formulation Two, current through a conductor is proportional to potential difference at its ends and inversely proportional to its resistance (Kenworthy 1961, p. 344). ${ }^{3}$ That was what Ohm himself said, except that he called resistance 'reduced length', the reason for which will become clear further. Some scholars objected to the use of the inverse proportionality between current and resistance calling it 'either a tautology or meaningless' (Campbell 1957, p. 59). The two formulations appear to contradict one another, because resistance is constant in one but varies in the other. In fact, this contradiction is only apparent, because they refer to different experiments and thus use different meaning of 'resistance'. Formulation One implies an experiment in which the conductor under investigation (whose resistance is $R$ ) is kept constant while some other conductors in the circuit are changed to change current. On the contrary, Formulation Two describes an

\footnotetext{
${ }^{3}$ See also the popular Internet websitehttp://en.wikipedia.org/wiki/Ohm's_law
} 
experiment, in which current is changed by replacing the conductor under investigation with other conductors.

Moreover, it is obvious that Formulation Two may actually refer only to a whole circuit rather than a part of it, because it is true only when $R$ is the total resistance of the circuit. In other words, Formulation Two for Ohm's Law for a part of the circuit is invalid. ${ }^{4}$

Another problem concerns the relation between resistance and Ohm's Law. Resistance is ordinarily introduced in the classroom by the equation

$$
R=\rho L / A
$$

where $L$ is a conductor's length, $A$ is the area of its cross section, and $\rho$ is a constant called resistivity. This equation implies that resistance depends only on properties of a conductor and it should be constant for a given conductor. If fact, resistivity may change, for instance, with a change of temperature or at certain voltages. The only way to establish that resistivity is constant is by proving that the resistance of the conductor in question is constant. To do this, one has to apply Ohm's Law for a part of the circuit in the form of

$$
R=V / I
$$

In other words, teachers use Ohm's Law to prove that resistance of a certain conductor is constant by means that presume that the law is true, or that the resistance is constant. Some students notice this logical circle, and usually teachers cannot clarify it.

If teachers would look for guidance in resolving this paradox to philosophers of science, they will not find much help. There was a suggestion to resolve the paradox by measuring resistance by other means, such as the Wheatstone Bridge (Kuhn 1974, p. 304). Yet, this device is also based on Ohm's Law.

In fact, neither Eqs. 3 nor 4 explains the meaning of resistance. As shown further, historically resistance was introduced as a measure of intensity of current, and $\mathrm{Ohm}$ obtained his law for the whole circuit while trying to determine how the intensity of current passing through a wire depended on the wire's length. To take into account the wire's diameter and material he introduced the notion of 'reduced length'. The Eqs. 3 and 4 were merely mathematical consequences of the law for the whole circuit and did not offer any independent physical meaning for resistance.

Still another difficulty is a confusion between proper areas of application of the two laws. Some educators create an impression that Ohm's Law for a part of a circuit is applicable for solving circuit problems. For instance, students are required to compare qualitatively brightness of electric bulbs in a circuit, in which the internal resistance of a battery and resistance of connecting wires are neglected (McDermott and Shaffer 1992). Obviously, this test was designed in the spirit of Ohm's Law for a part of the circuit.

In fact, Ohm's Law for a part of a circuit—if considered as a law and not merely a mathematical equation - has nothing to do with any circuits: it characterizes properties of a substance. ${ }^{5}$ This law has limits in its application, which are wider for some substances (metals) and narrower for others (gases). To determine whether this law holds or not at particular circumstances, one has to check whether resistance of a given conductor remains

\footnotetext{
${ }^{4}$ One may object to this that all resistances can be reduced to one to be used with Eq. 1. However such a consideration would ignore the specific roles of resistance of various parts of the circuit, such as meters, wires, and a power source. In particular, it will not explain warming up of the power source.

5 While some textbooks make this distinction clear (Weidner and Sells 1965, p. 737; Sears and Zemansky 1970, p. 391), others correctly describe the role of Ohm's Law for a part of the circuit but eliminate the law for the whole circuit (Harvard Project Physics 1975, p. 4/55).
} 
constant at different intensity of current passing through it. On the other hand, Ohm's Law for the whole circuit describes only circuits and does it without exceptions. This means that solving even qualitative circuit problems can and should be based on Ohm's Law for the whole circuit, by taking into account resistances other than those under investigation. Such problems would be more interesting and obviously more practical.

One may ask why, despite all these shortcomings, Ohm's Law for a part of a circuit receives more attention than the law for the whole circuit. Possibly, one of teachers' and textbooks authors' goals was to ease learning of Ohm's Law by simplifying calculations and physical considerations. They might have also desired to postpone introducing the difficult concept of electromotive force, if not skip it altogether. Also, a number of textbook writers spread false information that Ohm's Law for a part of a circuit was discovered experimentally while the law for a whole circuit can be easily deduced from the former from energy considerations (Sears and Zemansky 1952, p. 499; Beiser and Krauskopf 1964, p. 233; Weidner and Sells 1965, pp. 737, 765). This factor might have stimulated teachers to give the law for a part of a circuit a primary status. Whatever the motivations, this approach resulted in students' misunderstanding of the law and their inability to use it for practical purposes. If so, we may try to improve the situation by switching the focus from Ohm's Law for a part of a circuit to that for the whole circuit. In addition to reasons stated above, we have two more factors in favor of this idea: the origin of the law and the history of its teaching.

\section{Background of Ohm's Law}

Researches that immediately led to Ohm's Law began with Oersted's discovery of electromagnetism, although some preliminary work had been done earlier, first in static electricity and then in galvanic electricity.

Physicists described static electricity by two different parameters. One was measured by a deviation of an electrometer and called the degree of electricity (Cavendish 1771) or the electrical tension (Volta 1779): it characterized electricity at rest. The other one described electricity in motion and was measured by the strength of an electric shock, which was supposed to be in direct relation with the quantity of electricity. It was known that a charged Leyden jar insulated from other conductors displayed tension but no quantity of electricity. On the other hand, when a person closed a circuit by touching the knob and the outer wall of the jar, a shock proved a passage through a body of a quantity of electricity, but the jar showed no tension anymore. Of two Leyden jars charged to the same degree a larger one provided a stronger shock and was therefore characterized as storing a greater quantity of electricity. Here scientists employed to hydrostatic analogy in which quantity of electricity corresponded to quantity of water and tension, the hydrostatic pressure. Since it was not clear then whether a human body reacted to the total charge passing through it, or to its variation in time, the concept of quantity of electricity remained vague.

In 1800, Alessandro Volta (1745-1827) introduced a new kind of electricity, which had been called 'galvanic' due to its presumed identity with the electricity discovered by Luigi Galvani in 1791. Volta invented a device that became known as 'Volta's pile', which consisted of many couples of silver (or copper) and zinc separated by moistened pieces of cardboard. According to Volta, a contact of two different substances-best of all, metalscreated a force electromotive force that moved electricity in a certain direction, for instance, from zinc to copper. When many such couples were connected so that zinc of one was connected to copper of the other all the forces acted in the same direction. Thus if a 
pile consisted of $N$ identical couples, the total electromotive force of the pile was $N$ times that of one couple (Volta 1801). When the ends of a pile were connected by a circuit made of good conductors, it produced physiological effects, sparks, decomposed water, and other phenomena that were called at first galvanic and later, voltaic. It took several years to prove that the agent responsible for various actions of the pile was an electricity, somewhat similar to static electricity or electricity of the torpedo fish. One of the proofs was that similarly to a Leyden jar the pile affected an electrometer connected to its poles. For this reason, an insulated pile was also characterized by tension. The relative strength of effects produced in a closed circuit was presumed to depend on the quantity of electricity, obviously by analogy with a discharge of the Leyden jar.

All physicists considered electricity in a closed voltaic circuit as continuously moving, and some of them employed, albeit implicitly, a qualitative hydrodynamic model. This is evident from the usage of the term current, which was supposed to have a direction and a velocity (Volta 1802, Marum van 1801). In 1820, André-Marie Ampère (1775-1836) introduced a distinction of two types of voltaic phenomena, which he called electric tension and electric current (Ampère 1820). The former was applied to an open circuit, which showed electrical attraction/repulsion but no other electrical phenomena, while the latter referred to a closed circuit, which displayed no trace of attraction but a variety of other phenomena (chemical, physiological, thermal, and magnetic). Each of these terms referred to a status of electricity rather than a quantity. From that time on the term current became quite common, especially in France and Germany, and a new property of 'strength' or 'magnitude' was added to the early ones (Gilbert 1820; Becquerel 1823b). All these properties of current in conjunction with some new descriptive terms such as 'stream' or 'electricity flows' certify that in the 1820 s researchers were thinking of voltaic electricity as of running water rather than a flying projectile (Becquerel 1823b; Oersted 1823a, b). As for teaching purposes, the hydrodynamic analogy was introduced somewhat later (Péclet 1838, p. 261). Yet some physicists, especially British, avoided the term current speaking instead of 'galvanic action (or effect)' (Davy 1821a, b; Cumming 1822a, b).

The proponents of current began to describe the magnitude of a voltaic effect by means of a new term intensity of current (Gilbert 1820; Becquerel 1823a; Savary 1823) On the other hand, its opponents continued to use the quantity of electricity (Davy 1821). It is easy to see, however, that the meaning of quantity of electricity could not have been different from the intensity of current, which noted an amount of electricity passing through a crosssection of a conductor per unit of time. Indeed, usually descriptions of phenomena that required some time to develop, such as thermal or chemical, did not mention the duration of the experiment. This implies that quantity of electricity meant there not the amount of charge itself but rather charge/time. Thus, we may use intensity of current for the entire period under discussion without confusion. (The modern term current has a disadvantage of meaning both the status of electricity and a measurable parameter.)

While intensity of current implies a possibility of measurements, this had not been realized for quite a while. Although the French chemist Robertson suggested to measure the amount of gas released from a chemical decomposition as early as 1801, this technique did not find many followers. Some English experimenters tried to measure the release of heat by the length of a wire ignited by electricity (Wilkinson 1804). They believed to have proven that the length of the ignited wire was proportional to the surface area of a pile's plate, and since there was a presumption-by analogy with Leyden jar-that quantity of electricity was proportional to the plate's surface, the conclusion was that the length of the wire ignited by current was proportional to this quantity (Cuthbertson 1804, Children 1809). Yet, this method had its ambiguities: it was not clear which surface was of 
importance, of one plate or of all, nor how to combine series and parallel connections of the plates to burn the greatest length of a wire. For these reasons and a sheer inconvenience this method had not found practical application.

In 1821 a new stage of research of voltaic circuit began, pioneered by Humphry Davy (1778-1829), which concentrated on resistance of metals, or rather, according to the language of the time, on their conductive power or conductivity. The first interest in studying voltaic conductivity appeared soon after the discovery of Volta's pile. British scientists complained that Volta's theory gave the entire role in moving electricity to the electromotive force of bimetals and none to the liquid in the pile, although it was observed that a pile that used saline water provided much stronger shocks than a pile of the same tension using pure water. Volta replied that the difference resulted from a different conductivity of these piles, a saline solution being a much better conductor than pure water, because it adhered better to the metal plates due to a chemical interaction. In Volta's view, increasing the surface of contact between a plate and a liquid also improved conductivity, as was shown by stronger actions of piles with larger plates (Volta 1802, pp. 342-344). He also noticed that a shock felt by a person was stronger when his finger touching a pole was moist and still stronger when a part of his hand rather than a finger was immersed in a basin with water employed to close the circuit. He explained that water improved conductivity of the skin (Volta 1800, p. 299).

Johann Wilhelm Ritter (1776-1810) found that although actions of a pile in general increased with the number of its plates, there was always a limit after which adding more plates did not increase the effect. He explained this phenomenon as follows: while an increase of the number of cells raised the electromotive force it also reduced the overall conductivity, because a greater overall thickness of wet dividers separating metal plates meant a greater resistance. Ritter found that the limiting number was different for different phenomena, being the smallest for igniting wires, greater for chemical decomposition, and still greater for producing a shock (with the absolute numbers depending on the size of plates and the sort of liquid). He deduced from his observations a rule that a particular effect was the strongest when there was a certain correspondence between the conductivity of a pile itself and the conductivity of the body connecting it. For instance, in experiments with gluing wires conductivity of the external circuit was the greatest, therefore the conductivity of a required pile had to be relatively the greatest, which meant the smallest number of plates (but of large size). The circuit for decomposing liquids had a smaller conductivity, thus the required pile was to have more plates. Finally, a human body had an even smaller conductivity and therefore to achieve a strong shock one needed the greatest number of plates (all other circumstances being the same).

It is necessary to emphasize here that both Volta and Ritter estimated the degree of conductivity (or resistance) by the magnitude of an electrical effect. For instance, if the effect increased, this was due to an increase of conductivity (or decrease in resistance). This means, they treated conductivity as a magnitude directly related to intensity of current, while resistance was a property inversely related to intensity of current. In other words, conductivity (or resistance) was not an independent property of a circuit: it was determined—qualitatively at the time-by the intensity of current.

It has been suggested that their insight into the role of internal and external resistance (or, more exactly, conductivity) makes Volta and Ritter precursors of Ohm (Teichmann 2001). However, such a statement is way too strong. First, their conclusions were qualitative; second, thinking in terms of conductivity rather than resistance would have prevented Ritter from estimating an overall effect of a number of cells and conductors connected in series, even if that were his purpose; and finally, Ritter, had not been thinking 
of a voltaic circuit in general but rather of a specific circuit, which produced the greatest effect of each kind. Subsequently Volta's and Ritter's experimental results were confirmed or rediscovered by other physicists, yet they did not directly lead to Ohm's Law. Those that did were obtained only after Oersted's discovery of electromagnetism in 1820.

This discovery inspired some scientists to try electromagnetic effect as a better means to measure current than electro-thermal and electrochemical ones (Cumming 1822a). Davy, for instance, measured the electromagnetic effect of current by weighing iron filings attracted to a piece of a wire. This method did not find followers, however, as lacking convenience and precision. As a result, his conclusion that 'the effect was proportional to the quantity of electricity passing through a given space' did not make much of an impact (Davy 1821a, p. 11).

Although Davy was a pioneer in using electromagnetic effect, he preferred the old technique of electrochemical decomposition. He invented a new variety of it, measuring current by the number of cells it was capable of discharging 'completely', that is, until there was no sign of gas coming out of water. He found that wires of different length discharged different number of cells of the same pile. Davy's conclusion was that a wire's conducting power appeared to be inversely proportional to its length (Davy 1821b). Using the same technique and wires of the same material and length he showed that conducting power of a wire was proportional to its mass, which actually meant merely that it was proportional to the area of its cross-section. He also discovered that the conducting power of metallic bodies decreased when their temperature increased. With this knowledge, Davy took care in subsequent experiments to prevent wires from overheating by placing them in water. In particular, he measured the relative conductivity of different metals by comparing the number of cells discharged by the same piece of a wire, and also by comparing the length of wires from different metals discharging the same battery. Finally, he provided new evidence to resolve an old dispute of whether voltaic electricity propagated on the surface of conductors or inside them. He took two identical wires and flattened one making thus its surface six times larger than that of the other wire. Nonetheless, their conducting power turned out the same, which Davy saw as an argument against the surface propagation.

After 1821, all physicists followed Ampère's suggestion to measure electromagnetic effect by a deviation of a magnetic needle placed near a current-carrying wire. Ampère named a device based on this idea galvanometer. Yet, not everyone succeeded with the new technique of measurements, lacking a suitable experimental procedure. Rev. James Cumming (1776-1861), Chemistry Professor at Cambridge, was one of the first who explored magnetic deviation as a function of diameter and length of wire. Yet he discovered no definite function, because he changed the two simultaneously. On the other hand, he found evidence-probably independently of Davy - that voltaic current propagates inside a wire rather than on its surface (Cumming 1822a). Cumming also discovered that conductivity of the voltaic cell increased when the distance between its plates decreased (Cumming 1822b).

In 1821, Johann Schweigger (1779-1857), Professor of Chemistry at the University of Halle, built a galvanometer, in which a straight wire was replaced with a coil to increase magnetic effect of current. The idea was that if a magnetic needle is placed inside a current-carrying loop, the directions of magnetic forces created by the upper and lower parts of the wire coincide, and the total force is double of the one produced by a straight wire (Fig. 3). Likewise, if the wire makes several turns, the total force should be proportional to their number. Such a galvanometer became known as the 'electromagnetic multiplier'. 
(a)

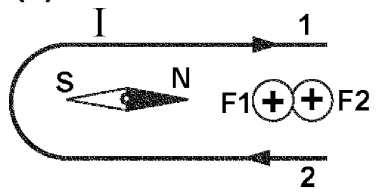

(b)

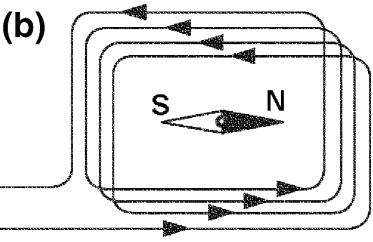

Fig. 3 An idea of an electromagnetic multiplier: (a) an effect of one turn, (b) an effect of many turns

Fig. 4 Becquerel's galvanometer-multiplier (From Becquerel 1826)

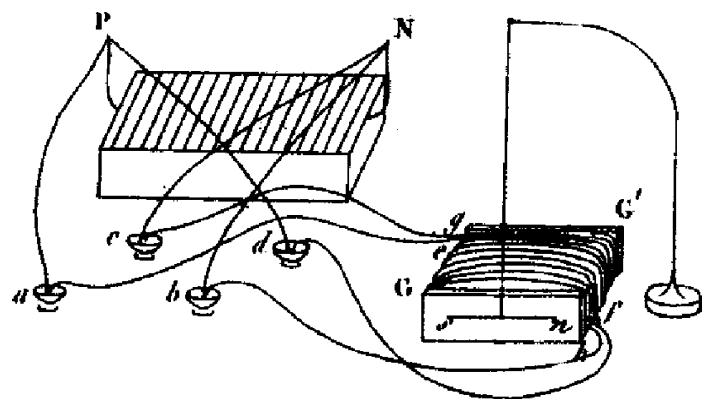

Antoine-César Becquerel (1788-1878) decided to use a multiplier, because he considered Davy's technique of discharging a pile rather crude: first, the signs of a 'complete discharge' were not exact, and second, Davy ignored a gradual discharge of the pile between different trials (Becquerel 1826). Becquerel eliminated the effect of gradual discharge by measuring currents running through different conductors at the same time rather than one after the other. To achieve this he made a multiplier GG' with two coils the ends of which were connected by wires $a e, b f, c g$, and $d h$, to tested wires and the battery through mercury cups $a, b, c$, and $d$ so that the two currents ran through the coils in the opposite direction (Fig. 4).

He assumed that the magnetic needle $s n$ placed inside the coils would decline one way or the other depending on which current was stronger, and if their intensities were equal, the needle would have rested in the initial position. Becquerel compared wires of the same material but differing in length and diameter and equalized the two currents by shortening one of the wires. He concluded that the two wires had the same conductivity when their lengths were proportional to their cross-sectional areas. Becquerel acknowledged that for wires of equal length his law was the same as Davy's, and also that that law meant that voltaic current ran inside a conductor. To determine relative conductivity of different metals Becquerel compared wires of the same diameter and took the ratio of their length as the relative conductivity. The advantage of Becquerel's method was in its precision, however it was not applicable to a comparison of wires of the same material and same diameter but different length. For this reason, Becquerel could not have contributed to solving a problem that became the focus of research on conductivity: how the conductivity of a wire depended on its length.

To compare intensity of current in different parts of a circuit Becquerel selected equal parts $a b$ and $a^{\prime} b^{\prime}$ of a long wire $P N$ closing the pile $A B M N$ (Fig. 5) and connected them to the multiplier by means of identical wires $a a, b b$, and so on, so that the currents in the coils ran in the opposite directions. When the two currents turned out equal, Becquerel concluded that intensity of current was either the same in all points of a circuit, or decreased in 


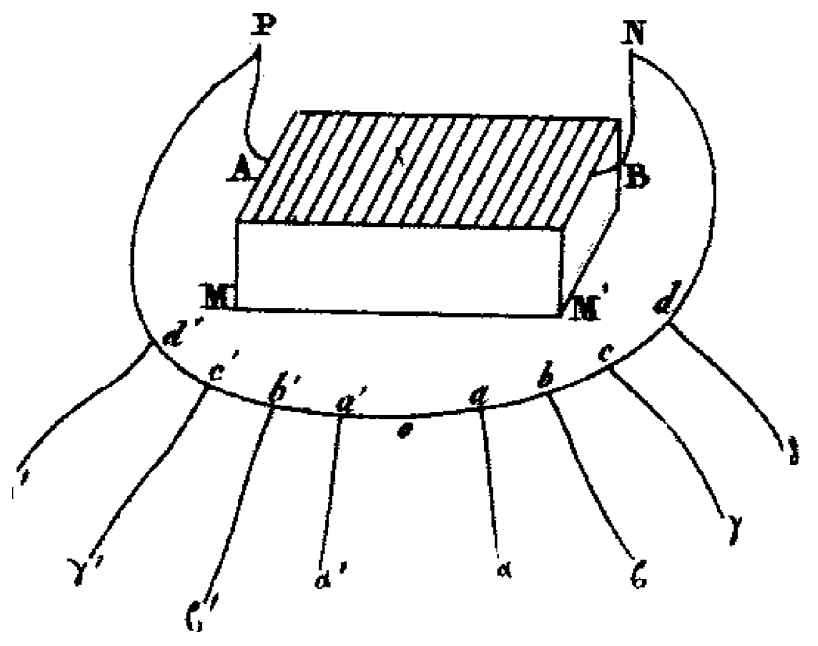

Fig. 5 The first use of a voltmeter (From Becquerel 1826)

arithmetical progression. The latter alternative was, of course, false, and one may be tempted to fault Becquerel's usage of parallel connection of the galvanometer instead of a series one.

In fact, the parallel connection was not a problem in itself. The problem was that the hypothesis of a uniformly decreasing current was easily verifiable, but Becquerel neglected to do so. Indeed, if the intensity of current is decreasing along its way, selecting $a b$ and $a^{\prime} b^{\prime}$, respectively, in the areas of the strongest and the weakest current, such as near positive pole and near negative pole or the middle of the wire, depending whether a singlefluid theory is employed or two-fluid theory, would created very different currents in the multiplier, which could not have balanced one another.

It had been already found that in fact a multiplier not always augmented the effect of current: this happened only when the length and diameter of its wire were in particular relation to those of the tested wires (Oersted 1823a, b). For this reason, Peter Barlow (1776-1862) decided to do his experiments on conductivity without a multiplier (Barlow 1825). His circuit (Fig. 7) was stretched along a rectangle $P G a b^{\prime} H N$ with an excess wire coiled around props $a b c d$ and $a^{\prime} b^{\prime} c^{\prime} d^{\prime}$. $K$ was a battery, $P$ and $N$ mercury cups, $B, C$, and $D$ were compasses measuring current in the long wire, and the compass $A$ did the same for a short 'standard' wire, which connected cups $P$ and $N$ between trials with the tested wires. The purpose of this 'standard' wire was to take into account a slow discharge of the battery during long experiments. Barlow was interested in feasibility of a long-distance electromagnetic telegraph communication, and since results of his initial experiments were not encouraging he decided to investigate the problem more thoroughly. He took the angle of magnetic deviation (or more exactly its tangent) as a measure of the magnetic 'effect'. Barlow deduced from his measurements that the 'effect' was about proportional to the square root of the length. He was less successful with diameter, finding no definite relation between the effect and the diameter of a wire.

Another subject of his interest was to verify whether magnetic deviation could help in establishing a theory of electricity. According to the single-fluid theory, if none of electricity was 'dissipated' or 'consumed' in the wire, the magnetic deviation should have been the same near the positive pole of the battery as near the negative pole. However, if some 
of the electricity was dissipated, a magnetic needle would have declined less near the negative pole than at the positive one. On the other hand, in two-fluid theory the current would have been the strongest at both poles and the weakest in the middle of the wire. To verify these hypotheses Barlow placed two magnetic needles near the ends of the wire and one near its middle with three observers watching them: the deviations of all the needles turned out equal within the margin of error (Fig. 6). He concluded that electricity did not dissipate along its way.

Thus, by the time Ohm entered the field in 1825 , a number of facts about voltaic current had been already established:

The intensity of current is the same throughout the circuit (Barlow).

Current propagates inside a wire (Davy, Cumming, and Becquerel).

Conductivity of a wire is proportional to its cross-sectional area (Davy, chemical effect).

Conductivity of two wires is equal if their lengths are in the same ratio as their crosssectional areas (Becquerel).

Conductivity of a wire is inversely proportional to its length, according to Davy (chemical effect) and Becquerel (magnetic effect, provided we accept \#3 as true). However, Barlow found conductivity to be inversely proportional to square root of the length (magnetic effect).

If one insists on calling the equation $R=\rho L / A$ one of Ohm's laws, as some scholars do, we see that this law was discovered prior to Ohm. However, we should not exaggerate the persuasiveness of its demonstration. Indeed, conductivity of a body had been viewed then as a property measured by intensity of current (or quantity of electricity) that presumably depended on the body, other factors being equal (tension, for one): an increase in intensity of current was attributed to an increase in conductivity of the body. The intensity of current meant the strength of a certain effect, which was measured, for instance, by the length of a wire burned, or by the amount of gas released, or by weight of filings attracted, or by deviation of a magnetic needle, etc. Since one could not have known that numbers obtained from different phenomena meant the same 'intensity of current', we should not give too much weight to Becquerel's confirmations of Davy's results. The term intensity of current acquired a universal meaning only when physicists began to use the same effect to measure currents produced in different phenomena. In particular, physicists adopted for this purpose a deviation of a magnetic needle only since 1825 .

Fig. 6 Barlow's circuit to measure current through a long wire (From Barlow 1825)

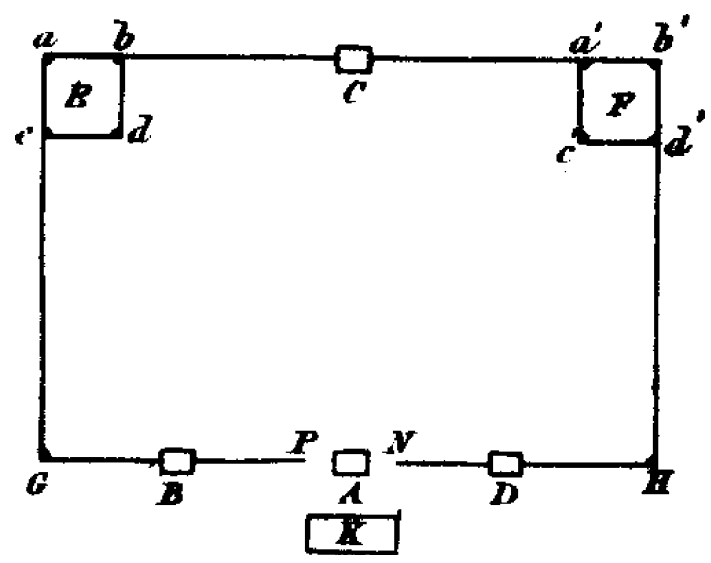




\section{Ohm's Discovery}

\subsection{Ohm's Experimerntal Laws}

When Ohm entered the field in 1825 with his first paper he had not known anything about his predecessors. Like Barlow he avoided a multiplier, because the role of its coil compared to tested wires was unclear. He suspended a magnetic needle $t t$ by a fine wire $s$ the torsion of which was measured by means of a pointer on a circular scale (Fig. 7).

A magnifier $l$ made reading of divisions on the scale more precise. For subsequent experiments $\mathrm{Ohm}$ employed a bismuth-copper a thermocouple made of a bismuth stick $a b b^{\prime} a^{\prime}$ joined to two copper bands $a b c d$ and $a^{\prime} b^{\prime} c^{\prime} d^{\prime}$. These bands end in mercury-filled cups $m$ and $m^{\prime}$ which served to make a contact with the tested wire. Like Barlow, Ohm faced the problem of gradual discharge of his pile during the first series of experiments, and he also used a 'standard' wire to take this discharge into account (Ohm 1825). Yet, he compared to the wire's length not the 'magnetic force' itself — or the magnetic deviationbut the 'loss of force', that is the difference between the readings for a given wire (the 'force') and the reading for the 'standard' wire (the 'normal force) divided by some standardized 'normal force' (McKnight 1967). The 'loss of force' $v$ turned out the following function of the wire's length $x$ ( $m$ and $a$ are constants):

$$
v=m \log (x+a)
$$

The unusual choice of the variable makes a comparison with the preceding results difficult, but a modern analysis shows that the equation was a good approximation for short wires Ohm used, whose resistance was probably smaller than that of his pile (Shagrin 1963).

Fig. 7 Ohm's galvanometer (From Ohm 1826a)

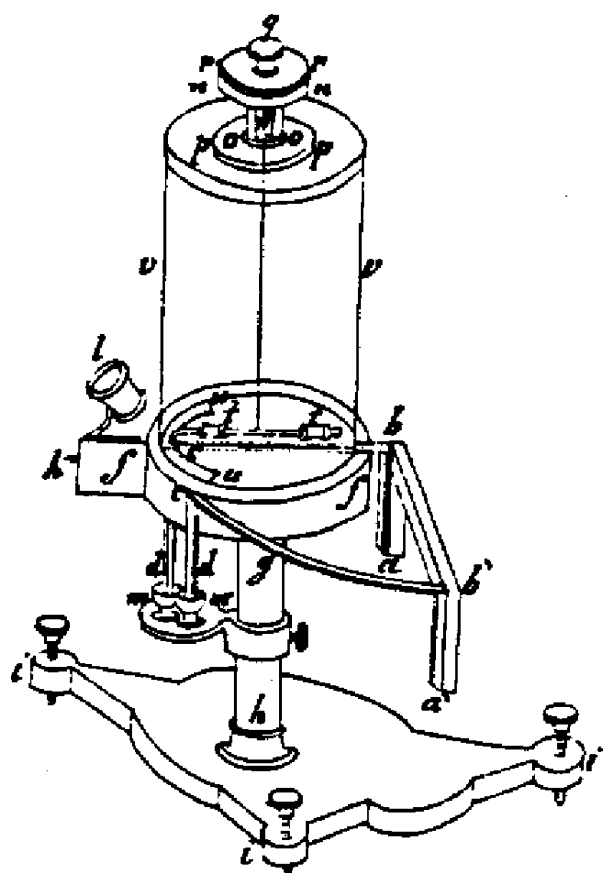


When Ohm had found out that his results differed from those of Becquerel and Barlow, he undertook a new series of experiments to overcome some flaws in his apparatus and procedures and achieve a greater precision. He replaced a pile with a thermoelectric source recently invented by Thomas Johann Seebeck (1770-1831), which provided a constant electromotive force. This eliminated the need in a 'standard' wire and measuring the 'normal' force, and the 'force' itself, that is, the reading on the dial, became Ohm's variable. Early in 1826 he published the following empirical equation between magnetic force $X$ and length of the wire $x$ ( $a$ and $b$ were constants) that satisfied the results of his new measurements:

$$
X=a /(b+x)
$$

By changing the temperatures at the thermocouple junctions Ohm found that $a$ varies while $b$ remains the same. Accordingly, he interpreted $a$ as the electromotive force $E$ of the power source and $b$ as resistance of the rest of the circuit, including the internal resistance of the source. If so, $b+x$ is the total resistance of the circuit. Assuming, as mentioned above, that intensity of current $I$ is a measure of the magnetic force $X$ and using the notation accepted above we obtain a familiar Ohm's Law for the whole circuit:

$$
I=E /(R+r)
$$

\subsection{The Potential}

In April 1826 Ohm published two new laws for voltaic circuits (Ohm 1826b). In modern notations, they looked as follows:

$$
\begin{gathered}
I=V A / \rho L \\
\varphi-\varphi_{0}=V x / L
\end{gathered}
$$

where $\varphi$ is potential at any inner point of a conductor whose distance from one of its ends is $x$, and $\varphi_{0}$ is potential at that end. The first equation is, in fact, a combination of two familiar laws $I=V / R$ and $R=\rho L / A$, while the second equation is new to us. It means that there is potential difference between any two points of a metal conductor, which is proportional to the distance between these points, varying from 0 to $V$. Ohm borrowed the idea of tension (or potential difference) that existed in a bimetal and transferred it to a metal conductor. However, the potential difference in a bimetal was due, according to Volta, to its heterogeneity (for instance, different metals), while Ohm's conductor was homogeneous. The assumption that there could be a potential difference between two points in a copper wire was a revolutionary idea, and it took time for many scientists to accept it.

Although Ohm mentioned potential as if being measured by an electrometer, there is no evidence that he used an electrometer for a closed circuit. He claimed to have verified the equation $I=V / L$, which was a specific case of Eq. 8 when all tested wires were of the same material and the same diameter (Ohm 1826a, p. 463). However, what he actually measured was the electromotive force of the thermocouple $E$ equal to tension between its two junctions. Since resistance of the thermocouple was close to zero, the potential difference across the wire $V$ was practically equal to $E$. Thus, in general, the concept of potential difference inside a conductor as expressed by Eq. 9 was a hypothesis unconfirmed by direct experiment, contrary to statements in some textbooks (McCormick 1965, p. 450). Its usefulness was demonstrated through confirmation of its various consequences. 


\subsection{Ohm's Theory}

Ohm's unpublished laboratory journal for 1825-1826 shows attempts to deduce theoretically his law for the whole circuit. He tried two different models of the flow of electricity: in one the current ran on the surface of a conductor, while in the other, inside the conductor. He assumed the magnetic force to be proportional to the outflow of current from an element of a wire, with the outflow being balanced by an inflow. To determine how the intensity of current (or magnetic force) depended on the length of the wire, he wanted to figure out how an infinitely small increase in the length of the wire $\mathrm{d} x$ affected the velocity of current change $\mathrm{d} v$. He tried two hypotheses: in one the velocity change was proportional to velocity itself, which agreed with the volume model, while, according to the other hypothesis, the velocity change was proportional to the square of velocity, which conformed to the surface model (Ohm 1825-1826). The latter hypothesis led to the empirically deduced Eq. 6, and this would have given Ohm much satisfaction had he not learned by that time that Davy and Becquerel had shown the surface model to be false.

Apparently, Ohm became frustrated with this theoretical investigation, for he never published it. Instead, a few months later Ohm came out with a totally different theory, some ideas of which appeared in a journal article (Ohm 1826b), with the whole theory published next year in a book form (Ohm 1827). The main innovation in the new theory was a hypothesis that the flow of electricity through an element of a conductor was proportional to the potential difference at the sides of this element. He followed in this the idea of Jean-Baptiste-Joseph Fourier (1768-1830) who assumed that the flow of heat was proportional to a temperature difference. The new concept of potential inside a metal played an important role in Ohm's theory, although it took time for physicists to recognize this. The theory did not serve to derive new equations verifiable by experiment, rather its purpose was to provide a rigorous mathematical derivation of his experimental law for the whole circuit (Eq. 2) in the style of Fourier and Laplace (Pourprix 1989).

\subsection{Reception Of Ohm's Law}

It is necessary to say a few words about the debate over the character of Ohm's Law, because students need to know about the roles of theory and experiment in discovering new laws of physics. Some laws, such as the principle of interference of light, originate from theoretical considerations, and are confirmed experimentally afterwards. Other laws are generalizations of the results of measurements and are interpreted theoretically after their discovery. As shown above, Ohm's Law for the whole circuit belongs to the latter category. Yet, a number of physicists, especially in France, challenged this claim arguing that Ohm's Law was deduced theoretically in his 1827 book. The reason for a special position of French physicists was that their compatriot Claude-Servais-Mathias Pouillet (17901868) rediscovered Ohm's Law for the whole circuit experimentally, and they wanted him to get some credit despite being late by several years (Pluvinage 1976). Pouillet's first result about conductivity of metals, included in the 1832 edition of his physics textbook, stated that conductivity of a wire would be exactly inversely proportional to the wire's length if one takes into account the resistance of the voltaic pile supplying the current (Pouillet 1832, p. 316). In 1837, he published a sort of a law for the whole circuit supported by experiment (Pouillet 1837a).

While a priority claim for a discovery repeated, even independently, 11 years later may look frivolous to us, French physicists thought they had good reasons to place the names of 
Ohm and Pouillet together (Müller 1845, Daguin 1863, p. 568) They believed that Ohm had deduced his law theoretically, which they deemed to be not as good as obtained experimentally, and that there had not been a proper experimental support for this law before Pouillet (Jamin 1866, p.102). While eventually some French textbooks writers found Ohm's articles of 1825-1826 (Gavarret 1858), the myth of the theoretical origin of Ohm's law persisted in France for a long time (Chappuis and Berget 1891, p. 146). It has been stated that Ohm's name appeared in print in France only in 1845, as a result of a dispute between Pouillet and another French physicist Eugène Péclet (Péclet 1845). The dispute was caused by Péclet who remarked in his textbook that Pouillet's equations for conductivity of metals were too complicated and offered his own version (Péclet 1838, p. 582). He did not provide any references to the source of ideas that stimulated his interest in this topic. However, Gabriel Lamé's (1840) textbook shows that some French physicists learned something about Ohm's work earlier than Péclet (Lamé 1840).

Such a delay with response to Ohm's work was not exclusive to France. In Germany only Gustav-Theodor Fechner (1801-1887) had recognized the importance of Ohm's Law right away and contributed to its experimental verification (Fechner 1831). However, for the next eight years the works published in German journals on the application of Ohm's Law were those by non-Germans, such as Russian physicists Moritz Hermann Jacobi (1801-1874) and Heinrich Friedrich Emil Lenz (1804-1865) and the Dutch scientist Pieter Vorsselman de Heer (Lenz 1835; Jacobi 1839; Vorsselman 1839).

English readers apparently have first learned about Ohm's Law in 1837 from articles by Lenz and Jacobi translated into the English (Jacobi 1837; Lenz 1837). At least, when Samuel Hunter Christie (1784-1865) published in 1833 the results of his investigation of how an induced current depended on the length and cross-sectional area of a wire, he did not mention Ohm among his predecessors (Christie 1833). To their credit, having familiarized themselves with Ohm's Law, British physicists quickly recognized its significance: in 1841, the Royal Society of London awarded Ohm the Copley Medal, Ohm's book was translated into English, and James Prescott Joule (1818-1889) used Ohm's Law in his research on heat produced by current (Joule 1841).

Physicists and scholars have tended to view the delay with recognition of Ohm's work as abnormal. One of the reasons offered to explain it was an insufficient experimental support (Jamin 1866, p. 102). Among other reasons there were philosophical prejudices and lack of appreciation of mathematics (Winter 1944). Among the internal difficulties, the hypothetical nature of potential difference in a homogeneous metal was named, as well as a combination of electrostatic and current phenomena in the same equation (Shagrin 1963, p. 546).

It is fair to say, however, that the delay with acceptance of Ohm's Law was rather a typical than an exceptional phenomenon in the history of science (Kipnis 2007). A perception of a new discovery is an individual matter, and probably the reasons mentioned above had influenced some individuals. There was yet another cause, however, that affected not only individuals but large groups of scientists: a meager exchange of scientific literature between different countries. Such an exchange was fully in hands of a few individuals. We see, for instance, that editors of the French leading physics journal Annales des Chimie et physique chose not review articles from German journals, while publishers of German physics journals did not donate them to the library of Paris Academy of Sciences as many other publishers did (Académie des Sciences de Paris 1910-1922). While Pouillet's article of 1837 was immediately translated into German and characterized as offering nothing new compared to works of Ohm and Fechner, this comment remained unknown in France (Pouillet 1837b, p. 281). The reason for Ohm's book reaching English 
readers earlier than the French was a decision by an English publisher Richard Taylor to begin in 1837 a new publication Scientific Memoirs devoted to translations of papers from foreign journals (Taylor 1837, pp. III, IV). Ohm's 1827 book appeared in the second volume of these Memoirs in 1841 (Ohm 1841). The dissemination of Ohm's Law could have been more successful had he followed the example of Oersted who himself sent copies of his paper to a number of institutions and individuals in Germany and other countries.

Another factor that could have delayed an interest in Ohm's Law even in the countries where it was known, was a perceived lack of practical applications. The situation changed since 1839 with a revival of interest in electromagnetic telegraph, for long telegraph lines required a careful consideration of the diameter of wires, batteries, and so on (Steinheil 1839; Vorsselman 1839; Wheatstone 1843).

These examples may be useful to students by showing that dissemination of scientific knowledge is not a strictly logical process, but the one that includes elements of chance, and that it can be affected by practical needs.

\section{Teaching Ohm's Law}

\subsection{The Early Approach}

In Ohm's (1827) book the law for a part of the circuit reads as follows:

The magnitude of current in any homogeneous portion of the circuit is equal to the quotient of the difference of the electrical force [potential] present at the extremities of such portion divided by its reduced length (Ohm 1827, p. 49)

The law for the whole circuit is:

The force of the current in a galvanic circuit is directly as the sum of all the tensions and inversely as the entire reduced length of the circuit, bearing in mind that at present by reduced length is understood the sum of all the quotients obtained by dividing the actual lengths corresponding to the homogeneous parts by the product of the corresponding conductivities and sections (Ohm 1827, p. 50).

While the former rule is mentioned only once, the latter law is used many times. This shows that Ohm considered the law for the whole circuit more important.

Nineteenth-century textbooks retained this priority by always presenting Ohm's Law for the whole circuit (Peschel 1846, Gavarret 1858, p. 67; Boutet de Monvel 1863) and occasionally the law for the part of the circuit, either deriving the latter theoretically (Chapuis and Berget 1891) or associating it with circuits using a thermocouple (Jamin 1866, Verdet 1868). This dominance of Ohm's Law for the whole circuit remained for a part of the twentieth century (Kimball 1917, p. 409; Duff 1925, p. 294). Later, however, the textbooks' authors shifted the emphasis to the law for a partial circuit, with the law for a complete circuit following it (Eldridge 1940, p. 423; McCormick 1965, pp. 454, 737; Halliday and Resnick 1978, pp. 684, 697). Some recent textbooks and Internet sources, however, frequently skip the law for the whole circuit altogether (Harvard Project Physics 1975, p. 4/55; Cohen 1976, p. 140). Apparently these changes aimed at making studying Ohm's Law easier. However, as mentioned above, they made the law incomprehensible and its 'verification' dubious. 


\subsection{Introducing Electrical Concepts in Historical Context}

The main idea of the new approach is that Ohm's Law may become made more comprehensible if it is introduced it the same sequence as it was discovered.

Attempts to use elements of the history of science in teaching science have already had a considerable history (Matthews 1994). While scholars and educators have never stopped debating pluses and minuses of the historical approach, some teachers continued to apply it without waiting for the final verdict. Many teachers, however, are still indifferent to it. Some scholars see an important reason for this failure in the fact that recommendations of historians and philosophers of science 'ignored teachers' overriding concerns with the learning of science concepts and the classroom imperatives of the context in which they work' (Monk and Osborn 1997, p. 406).

This author has always argued that the best way to engage teachers into using history is by convincing them that this can improve students' learning of scientific concepts, laws, and theories. This meant designing units that included historical materials together with the ways to introduce them to students (Kipnis 1992).

From a practical perspective, even when a comprehensive history-based physics courses is available, there is no need for a teacher to use it all in one year. It takes time to acquire the necessary knowledge and teaching techniques to use historical approach. Even a couple of well prepared topics per year may show the teacher that, indeed, some scientific concepts can be better understood if presented as in the process of discovery. Students will also get insight from these lessons into how scientific knowledge is created and how scientists work.

While there are different ways to present historical materials, students' experimentation-including a repetition of historical experiments-appears to be one of the most appealing to students (Lawrenz and Kipnis 1990). Experiment has always been important in teaching Ohm's Law, even without involving history, but approaching it historically may offer additional advantages.

First, the concepts of current, potential difference, electromotive force, and resistance become more comprehensible if introduced in their historical context. The main ideas are clear from the historical part presented above, and I outline them here only briefly, reserving the details for a separate paper.

It is recommended to start from potential difference, since it was introduced earlier than the other concepts. Students should know from the unit on static electricity that electrometer measures potential difference, for instance, between the knob and the bottom of a Leyden jar.

At the next step, the teacher introduces a galvanic battery, preferably in the form of several wet cells. Here potential difference between copper and zinc electrodes is measured by a voltmeter, which the teacher may characterize as a simple modern replacement of a sensitive electrometer employed by Volta. The result is defined as a measure of the electromotive force of the cell.

When the ends of a galvanic battery are connected by a good conductor, one may observe such effects as heat, shock, chemical decomposition, magnetic effect, and others. A measure of such an effect is introduced as the intensity of current.

Then the teacher defines resistance as a magnitude inversely proportional to the intensity of current. If, for instance, due to manipulations with parts of the circuit the intensity of current increases, we attribute the effect to a decrease in resistance of the circuit. With such a definition the meaning of the word 'resistance' is clear. 
Secondly, the history of Ohm's Law shows the origin of Eq. 4 for calculating resistance. Students can follow scientists who observed changes in the intensity of current produced by replacement of one conductor with another and determined factors affecting the changes, for instance, conductor's length or diameter. As shown below, students can deduce from such experiments, that resistance of a wire is proportional to its length and inversely proportional to the cross-sectional area.

Finally, the teacher can see from the historical section that the 'verification' of Ohm's Law for a part of a circuit is, in fact, an artificial exercise, for this law does not need verification. Ohm offered it not as an experimental law but rather as a definition of a new concept called potential difference (drop of voltage) between two points of a currentcarrying conductor. In other words, Ohm did not discover by measurements that potential difference equals current times resistance - this was done years later by Rudolf Kohlrausch (1809-1858)- he postulated it as a definition of the potential difference (Kohlrausch 1849).

Since potential difference was an electrostatic concept, Kohlrausch measured it by means of an electrometer, while he employed an electromagnetic ammeter to measure current. Since an electrostatic electrometer is now not available in school laboratories, teachers replace it with a voltmeter. However, while a voltmeter provides correct numbers, its usage violates the logic of the whole experiment, because voltmeter actually measures intensity of current. Voltmeter is essentially the same instrument as an ammeter and differs from it only by a much higher resistance, which allows voltmeter to be connected in parallel to the conductor to be measured. Let us imagine two identical meters one of which is connected in series with the conductor $R$ (Fig. 2) as 'ammeter $A$ ' and the other, in parallel to it as 'voltmeter $V$ '. A part $I_{\mathrm{V}}$ of the current $I$ is now diverted into $V$. Thus, the 'voltmeter' actually measures current, but this current is recalculated as voltage through the equation $V=I_{\mathrm{V}}\left(R_{\mathrm{V}}+R^{\prime}\right)$. But it does not make sense to 'verify' Ohm's Law by using a meter that is calibrated so as to take this law into account. Thus, the experiment with ammeter and voltmeter cannot verify (or confirm) Ohm's Law. It is better to take this law as given and use it to calculate current, drop of voltage, or resistance when the other two parameters can be measured.

With this in mind, the teacher may change the purpose of the experiment mentioned above from 'verification' of Ohm's Law for a part of a circuit to 'measuring resistance'. The teacher can make this exercise more meaningful by mentioning applications that require to measure resistance of a conductor to determine another parameter that influences resistance. The electrical thermometer is one of such applications.

\subsection{Introducing the Law for the Whole Circuit}

A proper introduction into a study of Ohm's Law for the whole circuit may begin with a demonstration that electromagnetic effect of current can be used for measurements. As the first step a teacher can use a home-made multiplier consisting of a compass and a removable coil (Fig. 8) The device is so simple and inexpensive that it can be made in sufficient quantity for a laboratory exercise. Connecting the multiplier to a battery through different resistors and an analog ammeter will demonstrate that magnetic needle moves synchronously with the ammeter's pointer, which means that the multiplier also measures current. The next step will be to show that an analog ammeter is based on an electromagnetic effect. If an open ammeter of a demonstration type is available, using it in the 


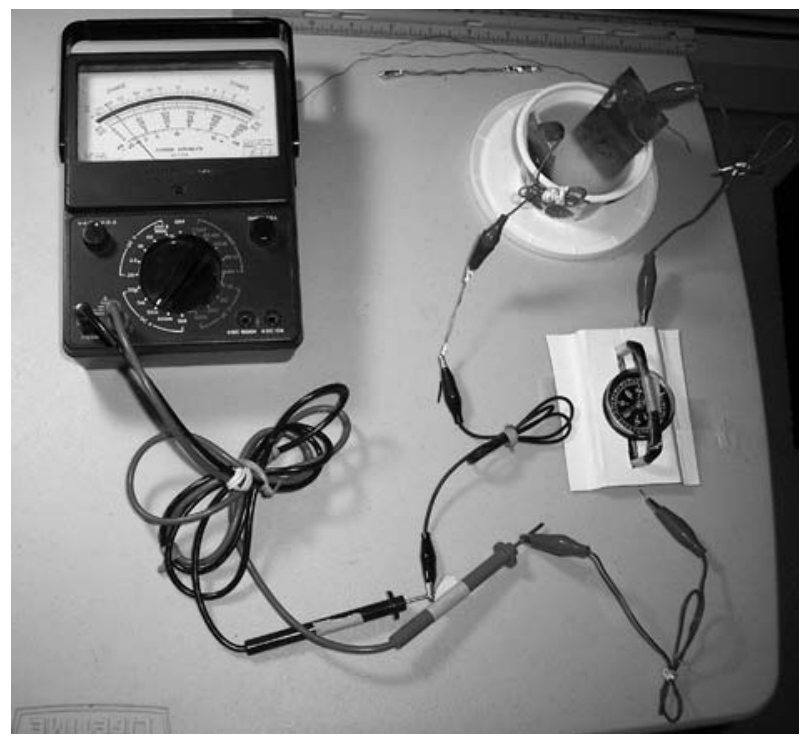

Fig. 8 Measuring current by means of historical and modern apparatus

experiment just described will make this point evident. If it is not available, a teacher should open a suitable analog meter, show its construction, and demonstrate how it works.

After this preparatory work the teacher offers a few experiments to demonstrate the meaning of resistance as a measure of intensity of current. In the first experiment, students keep the same resistor in the circuit and observe the ammeter while replacing the power source (a dry cell or a battery): they will see that intensity of current depends on the cell.

Next, students observe the ammeter while keeping the same battery and manipulating conductors in the circuit. They see that the intensity of current changes only when one of the conductors is removed from the circuit and replaced with a different conductor but not when the same conductor is moved to a different place of the circuit. In other words, students will get used to the idea that 'resistance' is actually a way to describe changes in the intensity of current, which characterizes the strength of a certain physical effect (in this case, the magnetic one). Thus, when seeing a decline of an ammeter's readings they may deduce that resistance in the circuit increased even without observing the actual manipulations with conductors (yet, they need to see the battery). At this point the teacher may reproduce, in a modified way, the first historical experiments that showed how resistance depends on length, cross-sectional area and material of a conductor.

The following group experiment is an example of a teacher-guided study of properties of electrical circuits that may lead to Ohm's Law. The dialogue itself is fictitious but the format of the experiment - a combination of an investigation with elements of history-as well as the plan of such an investigation are real and had been tested with science teachers. The plan included the following components:

\section{Plan of an Investigation}

\section{Preliminary Part}

1. Background (origin of the problem)

2. Initial observations/experiments 
3. Formulating a problem

4. Selecting variables

5. Selecting a procedure

II. Main Part

Variable 1

a. Preliminary experiments

b. Hypothesis

c. Test

d. Conclusion

Variable 2

a. Preliminary experiments

b. Hypothesis

c. Test

d. Conclusion

\section{General Conclusion}

IV. Discussion

The essential difference of this strategy from others currently in use has been described elsewhere (Kipnis 1996). In particular, an emphasis is made that the choice of variables and hypotheses is based on experiment rather than guessing. The Discussion section serves to compare students' work with that of the discoverers, which allows the teacher to touch upon various issues of the nature of science. This kind of experiments was a component of in-service physics courses taught to high-school teachers, who in turn tested it in their respective schools on a variety of topics of physics and other subjects. The dialogue form is written for a teacher. Such a form helps to emphasize a variety of results, which may be obtained in the experiment, and of which the teacher should be aware before preparing the apparatus for students' experiment. It also reflects some real features of these experiments as done by students, for instance, that all groups study the same variable simultaneously, and discuss their results before starting investigating another variable. Students were given blank forms to be filled in, which were based on the plan shown above.

\subsection{An Investigation of Resistance}

Teacher: We are going to learn some properties of electrical circuits by reproducing a few historical experiments, naturally, with some modifications. For instance, of the wires of high resistivity the most available is nichrome, which we will use instead of platinum wire in original experiments. Also, an ammeter will take place of a galvanometer. Nichrome wires can be salvaged from discarded heating devices, such as hair blowers. The wires can be mounted on wooden blocks or cardboard supports (the wires will not be hot) or even left loose (Fig. 8), because they will be connected by leads with alligator clips. Since we already know from history some results about how conductivity depends on length, diameter, and material of a wire, we may accept these variables as true, and we may also accept the results of Davy, Barlow, Becquerel, and Ohm as hypotheses. Our purpose will be to confirm or reject these hypotheses. Let us begin with diameter. 


\subsubsection{Variable 1: The Diameter of a Wire}

Student A: I could not find nichrome wires of different diameters, so I made several identical pieces $10 \mathrm{~cm}$ long and put some of them together sideways so that they touched along the whole length. In this way I obtained wires of a double and triple cross-section compared to a single wire, or, which is the same, two and three wires connected parallel to one another. If Davy was correct about conducting power changing as mass, I would expect the intensity of current to, respectively, double and triple. With a battery of three D-size cells a single wire $10 \mathrm{~cm}$ long created intensity of current of $1.9 \mathrm{~A}$, while the double wire increased the current to $2.1 \mathrm{~A}$, and the triple wire made $2.2 \mathrm{~A}$. Thus, the current is not proportional to the area. Was Davy mistaken?

Student B: What about Becquerel's result that $L / A=$ const? I found that a $5-\mathrm{cm}$ wire produced $2.04 \mathrm{~A}$. If we double both this length and area, we obtain two $10-\mathrm{cm}$ wires connected in parallel. According to Becquerel, this combination must produce the same result as a single 5-cm wire. And this is what we've got: 2.1 A compared to 2.05 A! Thus, we confirm Becquerel's hypothesis.

Student C: What is wrong with Davy's result? Is his equation not equivalent to that Becquerel? Davy said that when all conductors are of equal length current is proportional to the cross-sectional area.

Student B: He said 'conducting power' rather than 'intensity of current'.

Student $C$ : Have we not learned that the terms meant the same?

Student A: I've just realized that it would be the same only if conducting power referred to the whole circuit, but Davy meant only the wire.

Student $C$ : In other words, if the wire were the only conductor in the circuit, the intensity of current would be proportional to its area. But since there are other conductors, there no proportionality in our experiment. But I am still in the dark about Davy's result.

Teacher: This is an example of what I have mentioned above that different phenomena do not necessarily produce effects that numerically agree with one another. A 'full discharge' of a pile, which means a continually decreasing current, is difficult to compare to our steady current.

And now let us move on to study the length of the wire.

\subsubsection{Variable 2: The Length of a Wire}

Student A: I took a piece of wire about $30 \mathrm{~cm}$ long, connecting one lead to an end of this wire and another lead to any point of the wire (the leads were provided with alligator clips). By moving the second lead along the wire I could change the length connected to the circuit. With one D-size cell of $1.5 \mathrm{~V}$ the intensity of current was, 300, 320, 350, 380 , and $410 \mathrm{~mA}$ for the respective lengths of the wire of $30,25,20,15$, and $10 \mathrm{~cm}$. Student B: We see that although intensity of current decreases when the wire is longer, the decrease is less than proportional. Thus, Davy was certainly wrong, what about Barlow?

Student $C$ : The square root of the lengths $\sqrt{ } 30 / 10=1.73$, while the inverse ratio of currents is $410 / 300=1.37$. It looks like Barlow's equation is closer to the truth.

Student A: Apparently Davy's procedure was bad, because this is the second problem with his experiment. Perhaps Becquerel was right about criticizing Davy. 
Teacher: Occasionally scientists do make mistakes or use procedures that do not allow precise measurements. Yet, taking into account Davy's high reputation as an experimenter, before blaming him, let us look for other possible causes of the difference. You've already noted presence of other resistances, perhaps they can account for the difference between our results and Davy's.

Student A: We know nothing about our battery's resistance? If it does exist, how to measure it?

Teacher: To answer your questions, let us make a wet cell of Volta's type using a plastic cup filled with water and copper and zinc plates immersed into it (Fig. 8). Connect it the same way you connected the dry cell but use a shorter wire for a resistor. Having measured the current empty the cup, wipe out the electrodes, refill the cup with saline water, and repeat the experiment.

Student B: With water the intensity of current was $1.2 \mathrm{~mA}$, but a saline solution increased it by about 10 times!

Teacher: Volta reported a similar difference, although he employed a different meter: his perception of an electric shock. Let us now think about possible causes of this rise in the current.

Student B: The only thing we changed in this experiment is the liquid. Either of the two liquids is a conductor, because when I lifted one of the electrodes out of the liquid the ammeter showed zero, which means the circuit was broken. May we say that the intensity of current increased because saline water provided a smaller resistance than pure water?

Student $C$ : We saw that current also changed when we changed a dry cell. However, here we kept the same pair of electrodes, and according to Volta, their electromotive force depended only on the choice of metals but not on the liquid. But if the electromotive force remains the same, the only possible cause of the current change is a change in the resistance of the liquid.

Student A: This means that a wet cell has a resistance that depends primarily on the sort of the liquid. I also observed that current decreased when I lifted the electrodes halfway, but it increased somewhat when I moved the electrodes closer to one another. This may mean that resistance of a cell also depends on the surface of contact between liquid and an electrode and the distance between electrodes. In other words, speaking of the volume of the liquid conductor between the electrodes, its resistance increases when its crosssectional area decreases and when the length of this column increases, similar to the law for a solid conductor. Probably we can suppose from this that a dry cell also has resistance.

Student D: Is it not possible that Davy's pile had a resistance very small compared to his platinum wire?

Teacher: As described in other papers, he used small piles of 10 pairs of plates, which he connected to one another. In the experiment under discussion the connection appears to be parallel. And a parallel connection of $N$ identical piles reduces its internal resistance $N$ times. Thus, it might have been possible that Davy's pile had a very small resistance.

And now let us return to the initial question of the cause of discrepancy between your measurements and Davy's. You said that other conductors could have affected the current, including connecting wires, ammeter, and the cell. Adding conductivity of several bodies is not easy, but this is easy to do for their resistances. Let us, therefore, begin thinking in terms of resistance of how several consecutive conductors affect current. 
Student B: If the first obstacle slows down the current, the next one would slow it down even more, and so on. I would speculate that the total resistance should be a sum of resistances of all conductors connected in series.

Student $C$ : Which means that intensity of current cannot be inversely proportional to the length of a given conductor, for instance the wire, unless the resistance of the rest of the circuit, including the battery, is small compared to resistance of the wire.

Student D: Therefore, we may suppose that the intensity of current is inversely proportional to the total resistance of the circuit, which consists in our case of the nichrome wire, ammeter, connecting wires, and a battery. In other words, we assume that the intensity of current varies as follows (where $R_{1}, R_{2}, R_{3}$ are resistances of nichrome wires, $r$ is the resistance of the rest of the circuit, and $C=$ const):

$$
\begin{aligned}
& I_{1}=C /\left(R_{1}+r\right) \\
& I_{2}=C /\left(R_{2}+r\right) \\
& I_{3}=C /\left(R_{3}+r\right)
\end{aligned}
$$

Since we have four unknown resistances, we need one more equation, namely, for current produced when the circuit is closed without any nichrome wire $(R=0)$

$$
I_{0}=C /(0+r)
$$

Student A: But what is the meaning of $C$ ?

Teacher: Since you assumed it to be constant for the given battery whatever the wire in the circuit, this magnitude should characterize the battery. Also, by 1825 it had been known that the intensity of current increases with the number of cell in a battery, at times even proportionally, and that the electromotive force of a battery of $N$ identical cells would be $N$ times that of a single cell. Thus it was natural for Ohm and Pouillet to suppose that the constant $\mathrm{C}$ stands for the electromotive force of a battery. By combining this hypothesis with Eqs. 10 and 11 we obtain Ohm's Law for the whole circuit.

$$
I=E /(R+r)
$$

Student B: It is obvious that the intensity of current is not always proportional to the electromotive force of a battery. Indeed, we have for $N$ identical cells $E=N E_{1}$, $r=N r_{1}$, and $I_{1}=E_{1} / R+r_{1}$ (where $I_{1}, E_{1}$ and $r_{1}$ are, respectively, current, electromotive force, and resistance of a single cell). If we neglect all other resistances but those of the nichrome wire and the cell, we obtain

$$
I=N E_{1} /\left(R+N r_{1}\right)
$$

We see that $I=N I_{1}$ only when the resistance of a cell $r_{1}$ is very small compared to the resistance of the wire $R$.

Student C: Under such a condition, we also obtain Davy's result:

$$
I_{1} / I_{2}=R_{2} / R_{1}
$$

Teacher: Let us now use Eq. 11 to calculate the resistance of the wire. Remember that the electromotive force is measured by a voltmeter when the circuit is open. 
Student $B$ : I measured $E=1.4 \mathrm{~V}$ and $I_{0}=750 \mathrm{~mA}$. Thus, $r=1.4 / 0.75=1.9 \Omega$. Now, let us recall that the wires of 30,20 , and $10 \mathrm{~cm}$ long created currents of, respectively, 300,350 , and $410 \mathrm{~mA}$. By substituting $r$ and $I$ into Eq. 12 we obtain $R_{30}=2.8 \Omega$, $R_{20}=2.1 \Omega, R_{10}=1.5 \Omega$, etc. We see that resistances of wires of 30,20 , and $10 \mathrm{~cm}$ long are about proportional to their length. May we make a general statement that resistance is proportional to the length of a conductor?

Teacher: This is a very reasonable hypothesis, because it comes from experiment. If additional measurements will concur with this result, it will become a law.

Student A: Since we already know the resistance of the rest of the circuit $r$ we can use it to determine the role of cross-sectional area. Looking at the measurements for wires of different length that were all carried out at the range of ammeter of $500 \mathrm{~mA}$, I recalled that some of my early measurements with parallel wires exceeded $500 \mathrm{~mA}$, and I had to switch the range to $10 \mathrm{~A}$. Unfortunately, at the new range the result was not exactly the same. I don't know the reason for this, but I'd like to avoid switching the range.

Student B: You can achieve this by using longer wires. I've just tried three wires $30 \mathrm{~cm}$ long connected in parallel. Here are the results: $I_{1}$ (one wire) $=270 \mathrm{~mA}, I_{2}$ (two wires $)=360 \mathrm{~mA}$, and $I_{3}$ (three wires) $=450 \mathrm{~mA}$. When I rechecked the current for zero wire resistance, it turned out lower than before, $I_{0}=0.65$ A. Accordingly, $r=1.4$ / $0.65=2.1 \Omega$, which leads to $R_{1}=3.1 \Omega, R_{2}=1.8 \Omega, R_{3}=1.0 \Omega$. Thus, we have these resistances inversely proportional to their cross-sectional areas. I suppose this may be accepted as a hypothesis for all conductors.

\subsection{Discussion: Practical Considerations}

Teacher: Two comments are necessary here. The intensity of current changes when you switch the range of an ammeter, because this changes its resistance: the lower the range, the higher this resistance. That is why it is advisable to have all the measurements done within the same range. However, if necessary, the resistance of the meter can be measured or calculated and taken into account. As to the change in resistance $r$, it is due to changes inside the cell: the more a cell is discharged, the lower its electromotive force and higher its resistance.

So far we have used only Ohm's Law for the whole circuit, and we were able to measure resistance of conductors without knowing the law of resistance. Most of the time we used only an ammeter, which is an analog of a galvanometer with a multiplier. We used a voltmeter only to measure the electromotive force of a cell. In short, we have tried to imitate what Ohm's contemporaries did. To measure potential difference between two points of a circuit one needs a voltmeter, and such devices were not available at that time. For this reason, Ohm's Law for a part of the circuit had had no practical application for quite a while. Although an electrometer could have been employed to measure potential difference, this was difficult and inconvenient, and the first attempt to use it-merely to confirm Ohm's Law for a part of the circuit—was delayed by about 20 years.

Student A: It was interesting to learn how pioneers in electricity managed to do measurements without voltmeters and without Ohm's Law for a part of a circuit. However, today all this is irrelevant. To measure the resistance of a nichrome wire I make the wire together with an ammeter and a voltmeter a part of a circuit, measure the 
current through it and the drop of voltage across it and apply the equation $R=V / I$. Thus, we can do without Ohm's Law for the whole circuit.

Teacher: Before making any judgments, please do a few experiments in the way you suggested. Select a wire and make a new circuit to measure its resistance.

Student B: I took a nichrome wire $5 \mathrm{~cm}$ long and an $1.5 \mathrm{~V}$ dry cell, and observed that an analog multimeter employed as an ammeter showed $300 \mathrm{~mA}$ and a digital multimeter that served as a voltmeter, $120 \mathrm{mV}$. I calculated resistance of the wire as 0.120 / $0.300=0.4 \Omega$. When I connected the ammeter to the circuit by a different lead it showed $205 \mathrm{~mA}$, and the drop of voltage was $90 \mathrm{mV}$, which made the resistance equal to $0.44 \Omega$. We see that results of measurements may depend on connecting wires.

Student $C$ : I tried different $1.5 \mathrm{~V}$ cells-keeping everything else constant-and found the intensity of current varying from $480 \mathrm{~mA}$ ('D' cell) to $280 \mathrm{~mA}$ ('AA' cell). Probably, these cells had different internal resistances.

Student A: I discovered that when a voltmeter was connected exactly to the ends A and B of the nichrome wire (Fig. 2) it showed $160 \mathrm{mV}$, but when it was connected between $\mathrm{C}$ and $\mathrm{D}$ the reading was $480 \mathrm{mV}$. I didn't understand the reason for this, because there were no devices in the circuit between $\mathrm{A}$ and $\mathrm{C}$ or between $\mathrm{B}$ and $\mathrm{D}$, just copper wires. Had I used these numbers to calculate resistance of the nichrome wire, the results would have differed by a factor of three.

Student D: The drop of voltage between C and D is a sum of the voltage drops on the nicrome wire and the connecting wires. Your result shows that the latter was greater than the former, which means resistance of the connecting wires greater than that of the nichrome wire. When I replaced the nichrome wire with an $100 \Omega$ resistor the voltage drop at $C D$ was little larger than the one at $A B$, which means the resistance of connecting wires being very small compared to that of the resistor. Thus, resistance of connecting wires is significant only when the resistance under investigation is small.

Student B: A voltmeter, especially digital, has a very high resistance at most voltage ranges. Thus, connecting such a voltmeter to practically any conductor will not change current through it. It is not so with an ammeter. For instance, if we measure resistance of a wire in the range of $5 \Omega$ and resistance of the rest of the circuit is much smaller, one $1.5 \mathrm{~V}$ cell will produce the intensity of current about $300 \mathrm{~mA}$. To measure this current I would have to use the $500 \mathrm{~mA}$ range. At this range, the resistance of the ammeter part of the analog multimeter is about $0.7 \Omega$, as measured by the ohmmeter part of the digital multimeter. This means that the ammeter may change the overall resistance by $0.7 /$ $5=0.14$, or that the ammeter will introduce an error up to $14 \%$. This is too big an error! Student $B$ : If we use a $6 \mathrm{~V}$ cell, we would have to switch to $10 \mathrm{~A}$ range, at which the meter's resistance is very small.

Student $C$ : True, but this would introduce another source of error. With the reading of about $1.0 \mathrm{~A}$ and the smallest division of $0.1 \mathrm{~A}$ we have an error of about $10 \%$. Thus, choosing proper meters and power sources is not at all simple.

Teacher: You found that whatever had changed in the circuit, the ratio $R=V / I$ remained the same (within 10\%). This means that if the purpose is limited to measuring resistance of a conductor, the equation $R=V / I$ is sufficient. However, if we need to measure intensity of current and/or drop of voltage for other purposes, such as calculating maximal power or maximal current obtainable from a power source, we will need to know the internal resistance of the power source and resistances of various connecting wires. This means applying Ohm's Law for the whole circuit. You may use the law for a part of a circuit when you may neglect all the resistances but the one to be 
measured. But even in such a case before applying Ohm's Law for a part of a circuit you need to use mentally the law for the whole circuit to estimate that you may indeed neglect other resistances.

Student A: Is it not true that our experiments with an ammeter looked like an investigation to determine how current depends on the length of a conductor and its cross-sectional area?

Teacher: True, it was an investigation, although rather too sketchy. For instance, it was short of verification of the hypotheses for the length and the area. But it can be easily developed into a full-scale investigation.

Student B: It was very interesting to compare our results with those of Ohm's predecessors. One lesson I have learned from this comparison is that false laws-both Davy's and our first—originated not in an inappropriate apparatus or procedures but in a missing variable, such as resistance of the rest of the circuit.

\subsection{Using Analogies}

There is a considerable literature about using analogies in studying electric current (Iona 1979; Bauman 1980; Dupin and Joshua 1989; Buster 1995; Driver et al. 1994). One common mistake teachers make in using analogy is an attempt to find one such that would explain everything even in a limited field, such as electric circuits. In fact, teachers should encourage students to use different analogies to explain different aspects of the same phenomena. The history of Ohm's Law provides valuable examples of such complementary analogies.

Imagine a student working on an independent project who stumbled upon a strange phenomenon in an electric circuit and tries to explain it. At some point, the student may ask whether this goal would be achieved easier by resorting to an analogy instead of continuing experiments. The following fictitious dialogue, which comes from the investigation described above, may throw some light onto this problem.

Student A: We deduced two hypotheses from measurements. However, we conceived a 'true' hypothesis only after correcting the initial experiments, which we did after comparing our results with those of Davy and Barlow. What if we did not know about those historical cases? It appears that straightforward measurements do not necessarily lead to a correct hypothesis. If so, was there any other source for suggesting a correct hypothesis?

Teacher: Think of analogies!

Student B: I read that electricity resembles a flow of water. The amount of water coming through a cross-section of a pipe each second is proportional to its cross-section. Let us set the amount of water to be analogous to the quantity of electricity. Bearing in mind that the quantity of electricity passing per second is the intensity of current, which represents conductivity, we have to expect the conductivity to be proportional to the cross-sectional area of a conductor. Is it possible that Davy, Becquerel, and Ohm expected this result because they all relied on such a quantitative hydrodynamic analogy?

Teacher: There is no evidence that these scientists were guided by this analogy when selecting their experiments. Rather, it might have happened the other way around: their experiments established a basis for the quantitative hydrodynamic analogy, in particular, by proving that conductivity was proportional to the cross-sectional area. If the 
conductivity were found to be proportional to diameter of the wire instead the area, a competing model — of a surface flow-would have taken over (Arons 1999).

Student C: Where does this model come from?

Teacher: Static electricity travels only along the surface of a metal conductor.

Student D: May we use the hydrodynamic analogy to explain how resistance depends on the diameter and the length of a conductor? We know the fact that main water lines have very large pipes compared to those that come to a house. May we suppose that a wide pipe offers less resistance than a narrow one? Is it not true that in a wider pipe a greater proportion of water runs without friction, because it does not touch walls?

Teacher: Yes, a wider pipe offers less resistance, although this is not obvious: most of the friction is between layers of water rather than between water and walls. Thus, the 'friction' in electricity has no similarity with friction in water flow, and in this respect our analogy does not work. But, this does not invalidate the hydrodynamic analogy as such, because no analogy is true in all the parts of the two domains under comparison. What is important is that when limits of an analogy are established, it remains usable within these limits forever (Kipnis 2005). For instance, an important fact about the assumption of the friction taking place between water and the walls of a pipe is that it does not lead to any contradictions among conclusions deduced from hydrodynamic analogy for electricity. If so, the assumption is legitimate as a mnemonic device to remind one how resistance of a conductor is connected with its diameter. Perhaps you confuse two distinct notions: the rate of flow, or the amount of water passing per second through a cross-section of a pipe, and the velocity of water.

Student D: Still, I found a case when the hydrodynamic analogy leads to a contradiction. Indeed, the intensity of current is measured by a quantity of electricity passing through a cross-section per second, which is proportional to the cross-sectional area and the velocity of electricity. Two wires of a different diameter connected in series are analogous to two consecutive pipes of different diameters. Since water runs slower in a wider pipe, our analogy predicts that the intensity of current will be different in our two wires, which is nonsense. What is wrong in my reasoning? Is it not true that the role of resistance is in reducing velocity?

Teacher: There is no contradiction in the hydrodynamic part of the analogy: despite the difference in velocity, the rate of flow, or the amount of water running per second through a cross-section, will be the same in both pipes. This follows from the principle of continuity of flow of a liquid: a liquid runs so as not to leave any gaps in some parts of a conduit or accumulate in other parts, because such changes would stop the flow. The problem is in the electrical part of the analogy, and it consists in using two different definitions of the intensity of current. The first one is the 'official' definition by the quantity of electricity running through a cross-section of a conductor per second. According to this definition, the intensity of current will be the same in all conductors connected in series. The other definition states that intensity of current is proportional to the velocity of electricity. If we make velocity of electricity analogous to velocity of water, as shown above, this definition leads to a false law of a variable current in different parts of the same circuit. For this reason, this definition must be abandoned and velocity excluded from the parameters treated as similar under hydrodynamic analogy. This is what Ohm did after he had failed to come up with a satisfactory law of the decrease of velocity of the flow along its way. The teacher should tell students that velocity of the flow is beyond the limits of hydrodynamic analogy. That such limits exist, should not be surprising to students if they think that the hydrodynamic analogy does not explain the extremely fast propagation of electricity in metals. This is 
accounted for by another model, namely that electrical charges in metals are forced to move by an electromagnetic field traveling with a very high velocity. This model explains why all street lights in a city are lighted practically simultaneously. On the other hand, it does not provide a simple explanation of the laws of series and parallel connections. That is why we still continue to employ-where it is proper-the old hydrodynamic model (Stocklmayer and Treagust 1994).

Student A: If we ignore velocity, what do we do about two consecutive conductors of different diameter, in which the rate of flow is the same but resistance is different?

Student B: Perhaps we need to assume that resistance results not from slowing down electricity but from loss of some of its energy. Let us compare the flow of electricity to a motion of a body on a surface with friction. The longer the way, the more energy the body loses to overcome friction, which energy is transformed into heat. Likewise, an entire wire loses more electrical energy to heat than a part of it.

Student $C$ : I now understand why each additional conductor connected in series increases resistance, but I don't understand why adding a conductor in parallel to another one reduces the overall resistance of the circuit.

Student D: Perhaps, we may say that an additional parallel branch increases the transmission capability of the circuit, or increases the rate of flow. Imagine two holes in the bottom of a container with water, one of which can transmit $10 \mathrm{~cm}^{3} / \mathrm{s}$ and the other, $5 \mathrm{~cm}^{3} / \mathrm{s}$. If both holes are open at the same time, they will transmit $15 \mathrm{~cm}^{3} / \mathrm{s}$. This means an increase in the total rate of outflow. The same result will hold if we attach two pipes to the holes and connect them to a common pipe. In electrical terms, our analogy means that parallel connection increases conducting (transmitting) capacity, or the intensity of current.

Student A: I agree. This result is not at all trivial, and we would not have guessed it without using our analogy.

Student D: Are you saying that we should think of 'resistance' only as affecting the quantity of electricity transferred per second through a cross-section of a conductor regardless of the mechanism of this transfer?

Teacher: Exactly, and this is sufficient for solving many problems, although not all.

Student A: Which of the terms 'resistance' or 'conductivity' should we prefer?

Teacher: Either term can help in predicting properties of a circuit, and we use one or the other depending on circumstances. For instance, in the case of a series connection 'resistance' helps to realize that adding an extra conductor would increase the overall resistance and reduce the rate of flow. On the other hand, 'conductivity' is a more suitable term to predict that adding a conductor in parallel to a part of the circuit would increase the circuit's total conductivity, which means a lower total resistance and a greater intensity of current. Some scholars reported students' confusion created by false mechanical interpretation of the word 'resistance' (Viard and Khantine-Langlois 2001). Perhaps a wider use of the term 'conductivity' (or transmission capacity) may alleviate this problem to some degree (Johnstone and Mughol 1978).

Student B: I have a question about another analogy, of electricity being 'consumed' on its way. I know that some young students expressed such an idea while building their first electric circuits. But how such eminent physicists as Becquerel and Barlow could have thought of it?

Teacher: We can only speculate about this. Perhaps this idea is not unnatural. Imagine a rather long irrigation waterway. Do you agree that less water may exit this channel per second than enter it? 
Student $C$ : Yes. Unless the bed of this channel is covered with a waterproof material, some water will be absorbed by soil before reaching the field.

Teacher: For some reason, before Barlow no one had tried to test whether an electrical effect of current (for instance, chemical decomposition) would have been different in different parts of a circuit. Thus, any speculation appeared plausible. Since the electrical effect diminished with time, it was natural to suppose that something was lost in the circuit. The simplest hypothesis of this type would have been that some electricity was lost, or consumed to produce the chemical decomposition or another effect. An alternative hypothesis would be a loss of electrical energy rather than the electrical fluid. An analogy with several water mills set one after another along the same river would support such a hypothesis. However, the concept of energy could not have been used in the $1820 \mathrm{~s}$.

\subsection{Is Ohm's Law True?}

Having finished with Ohm's Law for the whole circuit the teacher should introduce the law for a part of a circuit. At first, it is recommended to offer it in Ohm's way, that is, as a definition of the difference of potentials between two points of a conductor $V$. The teacher should emphasize that the equation $V=I R$ was obtained from theoretical considerations rather than experiment. Accordingly, the teacher may recommend it primarily as a convenient mathematical device to calculate one of the three parameters when others two are known.

In addition to this, the teacher may offer a more modern interpretations of this law as $R=U / I$. One of its applications is studying resistance of a media as a function of various factors affecting its structure, such as heat, pressure, absorption of other substances, etc. Such a new interpretation of a law of physics is neither unusual nor suspect, because this is what had happened with time to a number of laws (Kipnis 2007).

And here is the place to discuss the status of Ohm's Law, since some philosophers deny its truth:

What is the status of claims that are typically cited as "laws of nature"-Newton's Laws of Motion, the Law of Universal Gravitation, Snell's Law, Ohm's Law, the Second Law of Thermodynamics, the Law of Natural Selection? Close inspection, I think, reveals that they are neither universal nor necessary-they are not even true (Giere 1999, p. 90, italics added)

At times this claim of falsity of laws is extended far beyond the few examples mentioned above, so that, for instance, 'most derived scientific laws are false' (Swartz 1985, p. 9).

In fact, teachers should not start worrying that they teach something false, for philosophers apply the term 'law' differently from scientists. Here is a description of the differences:

Physical laws are the 'real' laws of Nature. These laws are true independent of human beings coming to learn their truth... Physical laws have at least five properties. They are: (1) true (for all time and all place); (2) universal or statistical generalizations; (3) purely descriptive (i.e. free of any terms naming specific items in the universe); (4) conditional; and (5) contingent (i.e. not necessary [logical] truths)...Scientific laws, in contrast, are human creations. These are statements adopted in our collective effort to explain, predict and control the world...Scientific laws-with few exceptions-are understood (1) to be not literally true, i.e. to be 
false... In addition, scientific laws are understood (2) to be approximations to the truth, 'idealized' reconstructions, or instrumental tools; and (3) to be held only tentatively, always subject to the possibility, and in many instances the actuality, of refutation, abandonment, and replacement (Swartz 1995, p. 70, italics added).

This may be understood so that the laws physicists deal with are 'scientific' laws, which approximate the unknown 'physical' laws. If so, teachers may safely ignore the philosophers' concept of 'truth', which is applicable only to physical laws, and use the physicists' concept. To a physicist, Ohm's Law is true despite its limitations. Moreover, physicists presume that any law of physics has limits of its application, sometimes not yet discovered. They differ in this from philosophers who refuse to award the title 'law' to a limited concept.

An easy way to instill in students the idea that Ohm's Law has limits of applicability is by experimenting with a flashlight bulb. Students will note that when the bulb is lighted the voltage across this conductor stops being proportional to current. They will realize that the discrepancy between theoretical and experimental results increases with the current (everything else in the circuit being the same), and that up to a certain magnitude of current Ohm's Law holds quite precisely. As an outcome of this exercise, the teacher may inform students that the reason for an ohmmeter to provide correct measurements of resistance is its design that keeps the magnitude of current within proper limits. The teacher may also initiate a discussion of other factors that may increase the temperature of a wire, including comparing the amount of heat produced within a wire with the amount of heat dissipated by it. This may lead some students to an individual project of investigating the limits of current as a function of factors affecting the dissipation of heat.

The practical need in constantly validating Ohm's law for particular conductors brings back the issue of defining Ohm's Law for a part of the circuit. Since the only way to verify fulfillment of this law is by using equation $R=V / I$, it is clear that there is no need to include conditions for Ohm's Law (such as constant temperature) into its formulation. If the law holds, all conditions are fulfilled, but if it does not, we will not know without an investigation whether the condition broken was the one included into the formulation, or another one. Perhaps it would be reasonable to formulate Ohm's Law for a part of the circuit as follows: 'at certain conditions, the intensity of current through a conductor may be proportional to potential difference between its ends'. This implies that finding proper conditions for Ohm's Law is a necessary part of applying it, which is true for other laws of physics as well. As mentioned above, a limit on the intensity of current may be one of such conditions; others may be factors affecting dissipation of heat (diameter of the wire, insulation, etc.) and so on.

To show that conditions of applicability are not unique to Ohm's Law, the teacher may bring up other subjects, such as thermal expandability of solids or liquids: the length of a mercury column is proportional to temperature only up to a certain temperature.

Limitation of laws of physics is connected with the issue of the 'approximate truth', and the teacher should use an opportunity presented by some laws preceding Ohm's Law, including those expressing conductivity as a function of length by Davy, Barlow, and the 1825 law by Ohm, to address it. The teacher may explain that as long as the range of application of a particular 'false' law is determined, it will always be applicable within that range (for instance, for long conductors). Yet, the label 'false' prejudices one from using such a law. Thus, it makes more sense to call such a law 'partially true' or an 'approximation' rather than a 'false' law. True, some philosophers think that '[a]pproximate truth is not a kind of truth. Indeed, it is a kind of falsehood!'(Giere 1988, p. 106). Yet, the history of science shows that such philosophical concept of truth has never had much appeal to practitioners of science, and thus it should not be promoted in teaching science. 


\section{Conclusions}

Deficiencies in students' understanding Ohm's Law and their inability to apply it to achieve precise measurements suggest to shift the focus in studying Ohm's Law from the law for a part of the circuit to the law for the whole circuit.

One of the methods of introducing the law for a whole circuit is by following the logic of the discovery of Ohm's Law. It has several advantages over other methods.

One is in providing a correct understanding of the role and area of application for Ohm's Law for a part of a circuit, which eliminates some of the myths associated with it, including its experimental 'verification'. Another is an opportunity for students to do an experimental investigation that recreates some of the discoveries of Ohm and his predecessors. Students welcome an opportunity to 'play scientists', which allows them to develop creativity and critical thinking and improves their self-confidence.

Finally, the history of the discovery as discussed above provides a teacher with material to give students some insights into the nature of science and practice of science by scientists. Among them:

Laws of physics may be reinterpreted with time.

Some laws do not have to be proven at inception by direct experiments, because they rather serve to define a new physical concept.

The mathematical function in an experimental law may depend on a selected variable and an experimental procedure.

A law of physics has limitations in its usage.

A law once confirmed by some phenomena and later found to contradict other phenomena remains 'partially true', that is, true within the original range of applications, rather than 'false'.

Timing of acceptance of new laws and their subsequent development may be a subject to chance.

Scientists frequently use analogies between different phenomena, which are subject to experimental verification, and others.

Lack of space does not allow for a more detailed account of how to present these issues to students. This may become a subject for a separate paper. Such a paper should rely on several historical cases, because all the issues listed above are general and require a wider base for any generalizations. Some of these issues, especially those related to teaching the concept of 'scientific law' may be especially important for a school curriculum. Thus, more research is necessary about other laws prior to making any recommendations.

Acknowledgements The author thanks the administration of the Deutsches Museum Library for support that allowed him to study Ohm's manuscripts, Dr. Jürgen Teichmann for valuable discussions and various help, my wife Berta for help with drawings, and the reviewers for useful comments and suggestions.

\section{References}

Académie des Sciences de Paris (1910-1922) Procès-verbaux des séances de l'Academie, etc., 10 vols, l'Observatoire d'Abbadia, Hendaye (Basses-Pyrénées), vol 9 (1828/31), vol 10 (1832/35)

Ampère A (1820) 'Mémoire présenté à l'Académie royale des Sciences, le 2 octobre 1820, où se trouve compris le résumé de ce qui avait été lu à la meme Académie les 18 et 25 septembre 1820, sur les effets des courans électriques. Annales des Chimie et de Physique 15:59-76 
Arons A (1999) Inductive versus deductive teaching of concepts and theories: utilizing the historical framework. In: Proceedings of history, philosophy \& science teaching conference, University of Calgary, pp 49-63

Barlow P (1825) On the laws of electro-magnetic action, as depending on the length and dimensions of the conducting wire, etc. Edinb Philos J 12:105-114

Bauman RP (1980) Hydraulic models for electrical circuit elements. Phys Teacher 18(5):378-380

Becquerel AC (1823a) Du développement de l'électricité par le contact de deux portions d'une même metal, dans un etat suffisamment inégal de temperature, etc. Annales de Chimie et de Physique 23:135-154

Becquerel AC (1823b) Des effets électriques qui se development pendant diverses actions chimiques. Annales de Chimie et de Physique 23:244-258

Becquerel AC (1826) Du pouvoir conducteur de l'électricité dans les métaux, et de l'intensité de la force électrodynamique, etc. Annales de Chimie et de Physique 32:420-430

Beiser A, Krauskopf K (1964) Introduction to physics and chemistry. McGraw-Hill Books, New York

Boutet de Monvel B (1863) Cours de physique. L. Hachette, Paris, pp 515-516

Buster S (1995) Using the historical approach to avoid misconceptions in student's understanding of electricity. In: Finley F et al (eds) Proceedings of the third international history, philosophy \& science teaching conference. University of Minnesota, Minneapolis, MN, pp 170-175

Campbell N (1957) Foundations of science. Dover Publications, New York

Cavendish H (1771) An attempt to explain some of the principal phenomena of electricity, by means of an elastic fluid. Philos Trans R Soc Lond 61:584-677

Chappuis J, Berget A (1891) Leçons de physique générale, 3 vols. Gauthier-Villars, Paris, Version 2, p 147

Children JG (1809) An account of some experiments performed with a view to ascertain the most advantageous method of constructing the voltaic apparatus for the purposes of chemical research. J Natur Philos, Chem Arts 24:150-155

Christie SH (1833) The Bakerian lecture.-Experimental determination of the laws of magneto-electric induction in different masses of the same metal, and of its intensity in different metals. Philos Trans $\mathrm{R}$ Soc Lond 123:95-142

Cohen R (1976) Physical science. Holt, Rinehart \& Winston, New York et al

Cohen R et al (1983) Potential difference and current in simple electric circuits: a study of students' concepts. Am J Phys 51(5):407-412

Cumming J (1822a) On the connection of galvanism and magnetism. Trans Camb Philos Soc 1:269-279

Cumming $\mathbf{J}(1822 b)$ The application of magnetism as a measure of electricity. Trans Camb Philos Soc $1: 281-286$

Cuthbertson J (1804) Letter communicating an important and curious distinguishing property between the galvanic and electric fluids. J Nat Philos Chem Arts 8(97-8):205-206

Daguin P (1863) Cours de physique élémentaire. E. Privat, Toulouse; F. Tandu, Paris

Davy H (1821a) On the magnetic phenomena produced by electricity. Philos Trans R Soc Lond 111:7-19

Davy H (1821b) Further researches on the magnetic phenomena produced by electricity; with some new experiments on the properties of electrified bodies in their relations to conducting powers and temperature. Philos Trans R Soc Lond 111:425-439

Driver R et al (1994) Making sense of secondary science: research into children's ideas. Routledge, London

Duff A (1925) College physics. Longmans, Green and Co, New York

Dupin J, Johsua S (1989) Analogies and "modeling analogies" in teaching: some examples in basic electricity. Sci Edu 73(2):207-224

Eldridge J (1940) College physics, 2nd edn. Wiley \& Sons, New York

Fechner GT (1831) Massbestimmungen über die galvanische Kette, F.A. Brockhaus, Leipzig

Gavarret J (1858) Traité d'électricité, 2 vols. Victor Masson, Paris, vol 2

Giere R (1988) Explaining science: a cognitive approach. University of Chicago Press, Chicago

Giere R (1999) Science without laws. University of Chicago Press, Chicago, p 90

Gilbert LW (1820) Untersuchungen über die Einwirkungdes geschlossenen galvanische-lectrischen Kreises auf die Magnetnadel. Annalen der Physik 66:331-391

Halliday D, Resnick R (1978) Physics, parts 1 \& 2 combined, 3rd edn. Wiley, New York, etc., p 682

Harvard Project Physics (1975) Project physics text. Holt, Rinehart and Winston, New York, Unit 4, p 55

Iona M (1979) Teaching electrical resistance. Phys Teacher 17(5):299-305

Jacobi MH (1837) On the Application of Electro-Magnetism to the Movement of Machines. In: Taylor R (ed) Scientific Memoirs, vol 1. Taylor, London, pp 503-531

Jacobi MH (1839) Ueber das chemische und das magnetische-Galvanometer. Annalen der Physik 48:26-57

Jamin J (1866) Cours de Physique de l'École Polytechnique, 3 vols. Gautiers-Villars, Paris, vol 3, pp 106109

Johnstone A, Mughol A, (1978) The concept of electrical resistance. Phys Edu 13(1):46-49 
Kenworthy R (1961) College physics. F. Davis, Philadelphia

Kimball A (1917) A college textbook of physics, 2nd edn. Holt \& Co, New York

Kipnis N (1992) Rediscovering Optics. BENA Press, Minneapolis, MN

Kipnis N (1996) The 'historical-investigative' approach to teaching science. Sci \& Edu 5:277-292

Kipnis N (2005) Scientific analogies and their use in teaching science. Sci \& Edu 14(1):199-233

Kipnis N (2007) Discovery in science and in teaching science. Sci \& Edu 16(9-10):883-920

Kohlrausch R (1849) Die electroscopische Eigenschaften der geschlossenen galvanischen Kette. Annalen der Physik 78(1):1-21

Kuhn T (1974) Second thoughts on paradigms. In: Suppe F (ed) The structure of scientific theories. University of Illinois Press, Urbana, IL

Lamé G (1840) Cours de Physique de l'École Polytechnique, 3 vols, 2nd edn. Bachelier, Paris, vol 3, pp 325, 332

Lawrenz F, Kipnis N (1990) Hands-on history of physics. J Sci Teacher Edu 1(3):54-59

Lenz HFE (1835) Ueber die Leitingsfähigkeit der Metalle für die Elektricität beiverschiedenen Temperaturen. Annalen der Physik 34:418-437

Lenz HFE (1837) The Laws of the Conducting Powers of Wires of different Lengths and Diameters for Electricity. In: Taylor R (ed) Scientific Memoirs, selected from the Transactions of Foreign Academies of Science and Learned Societies, and from Foreign Journals, vol 1. Taylor, London, pp 311-324

Matthews M (1994) Science teaching: the role of history and philosophy of science. Routledge, London

McCormick WW (1965) Fundamentals of college physics. Macmillan, New York

McDermott L, Shaffer P (1994) Research as a guide for curriculum development: an example from introductory electricity. Part I: Investigation of students' understanding. Am J Phys 60(11):994-1003

McKnight J (1967) Laboratory notebooks of G. S. Ohm: a case study in experimental method. Am J Phys 35:110-114

Monk M, Osborne J (1997) Placing the history and philosophy of science on the curriculum: a model for the development of pedagogy. Sci Edu 81:405-424

Müller J (1845) Lehrbuch der Physik und Meteorologie,...der Bearbeitung von Pouillet's Lehrbuch der Physik, 2 vols, 2nd edn. F. Biweg \& Son, Braunschweig, vol 2

Oersted HC (1823a) Nouvelles expériences de M. Seebeck sur les actions électro-magnétiques. Annales de Chimie et de Physique 22:199-201

Oersted HC (1823b) Sue le Multiplicateur électro-magnetique de M. Schweigger, et sur quelques applications qu'on en a faites. Annales de Chimie et de Physique 22:358-365

Ohm GS (1825) Forläufige Anzeige des Gesetzes, nach welchem Metalle die Contactelectricität leiten. Annalen der Physik 4:79-88

Ohm GS (1826a) Bestimmung des Gesetzes nach welchem Metalle die Contactelectrizität leiten, etc. Jahrbuch der Chemie und Physik 44:137-166

Ohm GS (1826b) Versuch eine Theorie der durch galvanische Kräfte hervorgebrachten electroscopischen Erscheinungen. Annalen der Physik 6:459-469; 7:45-54, 117-118

Ohm GS (1825-1826), Laboratory Journal for 1825-1826, Ohm Collection, Deutsches Museum Library, Item. 904. Pages in this manuscript are not numbered

Ohm GS (1827) Die galvanische Kette mathematisch bearbeitet. T.H. Riemann, Berlin; Facsimile (1969) Culture et civilization, Bruxelles. See an English translation: Ohm GS (1891) The galvanic circuit investigated mathematically. D. van Nostrand Co., New York; Facsimile (1969) Kraus Reprint Co., New York

Ohm GS (1841) The Galvanic Circuit investigated Mathematically. In: Taylor R (ed) Scientific Memoirs, vol 2. Taylor, London, pp 401-506

Péclet E (1838) Traité élémentaire de physique, 3 vols, 3rd edn. Hachette, Paris, vol 2

Péclet E (1845) Lettre touchant un passage de la dernière édition du Traité de Physique de M. Pouillet. Comptes rendus hebdomadaires des séances de l'Académie des Sciences 20:54-60

Peschel C (1846) Elements of physics, 3 vols, transl. from the German, Longman et al., London, vol 3, p 106

Pouillet CSM (1832) Ėlémens de physique expérimentale et de météorology, 2nd edn. chez Béchet jeune, Paris, vol 1, pp 316-318

Pouillet CSM (1837a) Mémoire sur la pile de Volta et sur la loi génerale de l'intensité que prennent les courants, soit qu'ils proviennent d'un seul élement, soit qu'ils proviennent d'une pile à grande ou à petite tension. Comptes rendus hebdomadaires des séances de l'Académie des Sciences 4:267-279

Pouillet CSM (1837b) Ueber die Volta'sche Säule und über das allgemeine Gesetz für die Intensität der Ströme, etc. Annalen der Physik 42:281-296 (esp note p 281)

Pourprix B (1989) La mathématisation des phénomènes galvaniques par G.S. Ohm (1825-1827). Revue d'Histoire des Sciences et de leurs Applications 42:139-154 
Pluvinage Ph (1976) Quelques épisodes de la carrière d'un grand phycisien Franc-Comtois: Claude-ServaisMathias Pouillet (1790-1868). Mémoires de la Societé d'émulation du Doubs, pp 59-77

Ritter JW (1805) Neue Versuche und Bemerkungen über den Galvanismus. Zweiter Brief. Annalen der Physik 19(1):17-44

Savary F (1823) Extrait d' un mémoire lu à l'Academie des Sciences, le 3 février 1823.Annales de Chimie et de Physique 22:91-100

Schagrin ML (1963) Resistance to Ohm's law. Am J Phys 31:536-547

Sears F, Zemansky M (1952) College physics. Complete edition, 2nd edn. Addison-Wesley, Reading, MA

Shaffer P, McDermott L (1992) Research as a guide for curriculum development: an example from introductory electricity. Part II: design of instructional strategies. Am J Phys 60(11):1003-1013

Shipstone (1984) A study of children's understanding of electricity in simple DC circuits. Eur J Sci Educ 6(2):185-198

Steinheil CA (1839) Upon Telegraphic communication, especially by means of Galvanism.In: Sturgeon W (ed) The Annals of Electricity, Magnetism, \& Chemistry, vol 3. Sherwood, Gilbert, \& Piper, London, pp 439-452, 509-520

Stocklmayer SM, Treagust DF (1994) A historical analysis of electric currents in textbooks: a century of influence on physics education. Sci \& Edu 3:131-154

Swartz N (1985) The Concept of Physical Law. Cambridge University Press, Cambridge

Swartz N (1995) A neo-Humean perspective: laws as regularities. In: Weinert F (ed) Laws of nature essays on the philosophical, scientific and historical dimensions. Walter de Gruyter. New York, pp 6791

Teichmann J (1976) 150 Jahre Ohmsches Gesetz - 1826 bis 1976. Electrotechnische Zeitswchrift A 97(10):594-600

Teichmann J (2001) Volta and the quantitative conceptualization of electricity: from electrical capacity to the preconception of Ohm's law. In: Bevilacqua F, Fregonese L (eds) Nuova Voltiana: studies on Volta and his times, vol 3. Università degli Studi, Pavia; Editore Ulrico Hoepli, Milano, pp 53-80

Verdet É (1868) Cours de Physique professé à l'École Polytechnique, 2 vols, V. Masson, Paris, vol 1, pp 373,404

Viard J, Khantine-Langlois F (2001) The concept of electrical resistance: how Cassirer's philosophy, and the early developments of electric circuit theory, allow a better understanding of students' learning difficulties. Sci \& Edu 10:267-286

Volta A (1779) Sur la capacité des conducteurs électriques \& sur la commotion égale à celle de la bouteille de Leyde que peut donner un simple conducteur. Observations sur la physique 13:249-277

Volta A (1800) On the electricity excited by the mere contact of conducting substances of different kinds. Philos Mag 7:289-311

Volta A (1801) De l'électricité dite galvanique. Annals de Chimie 40:225-256

Volta A (1802) Au Redacteurs de la Bibliothéque Britannique. Bibliothéque Britannique 19:274-289, 339_ 350

Vorsselman P de Heer (1839) Theorie der elektrischen Telegraphie, etc. Annalen der Physik 46:513-537

Weidner R, Sells A (1965) Elementary classical physics, Version 2, Allyn \& Bacon, Boston

Wheatstone $\mathrm{CH}$ (1843) Bakerian Lecture.- An Account of several new Instruments and Processes for determining the Constants of a Voltaic Circuit. Philos Trans R Soc Lond 133:303-327

Wilkinson C (1804) Facts upon which deductions are made to shew the law of Galvanism. J Nat Philos 7:206-209

Winter H (1944) The reception of Ohm's electrical researches by his contemporaries. Philos Mag 35(245):371-386

\section{Author Biography}

Nahum Kipnis is a Consultant in Science Education. He was born and educated in the former USSR, where he received MS in physics and mathematics. He taught high-school and college physics and did research in experimental physics and the history of science. In 1979, he emigrated to the USA, where he received a Ph.D. in the history of science from the University of Minnesota in 1984. His research focuses on the history of optics and electricity, methodology of science, and teaching science from a historical perspective. His publications include History of the Principle of Interference of Light (Basel: Birkhäuser Verlag, 1991); Rediscovering Optics (Minneapolis: BENA Press, 1992), and a number of articles. 